\title{
Training-induced improvement of response selection and error detection in aging assessed by task switching: effects of cognitive, physical, and relaxation training
}

\section{Patrick D. Gajewski * and Michael Falkenstein}

Leibniz Research Centre for Working Environment and Human Factors, Dortmund, Germany

\section{Edited by:}

Torsten Schubert, Ludwig-Maximilians

University Munich, Germany

Reviewed by:

Jutta Kray, Saarland University,

Germany

Bruno Kopp, Klinikum Braunschweig,

Germany

\section{*Correspondence.}

Patrick D. Gajewski, Leibniz Research Centre for Working Environment and

Human Factors, Ardeystr. 67, D-44139

Dortmund, Germany.

e-mail: gajewski@ifado.de
Cognitive control functions decline with increasing age. The present study examines if different types of group-based and trainer-guided training effectively enhance performance of older adults in a task switching task, and how this expected enhancement is reflected in changes of cognitive functions, as measured in electrophysiological brain activity (eventrelated potentials). One hundred forty-one healthy participants aged 65 years and older were randomly assigned to one of four groups: physical training (combined aerobic and strength training), cognitive training (paper-pencil and computer-aided), relaxation and wellness (social control group), and a control group that did not receive any intervention. Training sessions took place twice a week for $90 \mathrm{~min}$ for a period of 4 months. The results showed a greater improvement of performance for attendants of the cognitive training group compared to the other groups. This improvement was evident in a reduction of mixing costs in accuracy and intraindividual variability of speed, indexing improved maintenance of multiple task sets in working memory, and an enhanced coherence of neuronal processing. These findings were supported by event-related brain potentials which showed higher amplitudes in a number of potentials associated with response selection (N2), allocation of cognitive resources (P3b), and error detection (Ne). Taken together, our findings suggest neurocognitive plasticity of aging brains which can be stimulated by broad and multilayered cognitive training and assessed in detail by electrophysiological methods.

Keywords: aging, cognitive training, physical training, task switching, response selection, ERPs, N2, Ne

\section{INTRODUCTION}

The primary role of executive or control functions is planning, maintaining, and implementing of goal-directed behavior. This behavior requires a number of distinct cognitive abilities like working memory, selective attention, multitasking, task switching, response monitoring, and error detection. Nearly all of these functions show an age-related decline (Craik and Salthouse, 2000; Band and Kok, 2000; Falkenstein et al., 2000, 2001, 2002; Kray and Lindenberger, 2000; Verhaeghen and Cerella, 2002; Salthouse, 2009). However, the decay of these functions is extremely different among individuals, and some of them preserve a high functional level until very old age whereas other's cognitive abilities decrease already in the middle of adolescence (Baltes and Lindenberger, 1997; Hultsch and MacDonald, 2004). Thus, the investigation of factors preventing cognitive decline, the development of methods for compensation as well as interventions to improve fluid cognition in elderly plays a crucial role for maintaining quality of life in older age.

Indeed, in recent years, there is an increasing interest in factors ameliorating cognitive and brain aging. Whereas genetic dispositions set an individual range of cognitive abilities, which are even magnified in late relative to early adulthood (Lindenberger et al., 2008), variable factors like nutrition or level of physical, social, and cognitive engagement can provide stimulation of the cognitive system that can reduce some age-related deficits (Bielak et al.,
2007; see also Greenwood and Parasuraman, 2010 and Gajewski and Falkenstein, 2011a for reviews).

The most consistent improvements of control functions in older age were found after physical exercise (see Colcombe and Kramer, 2003; Kramer and Erickson, 2007; Hillman et al., 2008, for reviews). For example, Colcombe et al. (2004) showed that older participants improved performance in an executive function task and showed larger activation in brain areas supporting these functions after a 6-month cardiovascular training. Smiley-Oyen et al. (2008) compared effects of aerobic and strength training in older persons on executive control tasks and found largest benefits of the aerobic training after 5 months training. Similar effects on executive functions in elderly were reported by LiuAmbrose et al. (2010) after 1 year resistance training. Recently, Voelcker-Rehage et al. (2011) reported differential effects of 1 year cardiovascular and coordination training on executive control and perceptual speed tasks as well as effects on the underlying brain activity measured by fMRT. These findings suggest that not only aerobic training but also other types of physical activity are beneficial regarding cognitive functions. Thus, combination of different types of training like aerobic and strength exercises may be more beneficial than only one type as different neuronal structures are involved (Colcombe and Kramer, 2003; Heyn et al., 2004; Kramer et al., 2006). Indeed, Colcombe and Kramer (2003) and McAuley 
et al. (2004) argued that a combined cardiovascular and strength training would be most promising regarding cognitive improvements. The neuronal mechanisms of aerobic exercise on executive functions are not entirely clear but animal and human research suggest enhanced neurogenesis and synaptic plasticity stimulated by higher concentrations of brain-derived neurothrophic factor (BDNF), particularly in the hippocampus, a brain area strongly associated with learning and memory (van Praag et al., 1999, 2005; Wiskott et al., 2006; Erickson et al., 2011; Gajewski et al., 2011).

A second possibility to enhance cognitive functions in aging is formal cognitive training that focuses either on one domain only, for example memory (Klingberg et al., 2002; Jaeggi et al., 2008), attention (Green and Bavelier, 2003), visual search (Becic et al., 2008), dual task (Bherer et al., 2005), or task switching (Minear and Shah, 2008; Karbach and Kray, 2009). In the earlier studies the training effects were indeed restricted to the trained function and did not transfer to other functions or daily activities (e.g., Willis and Schaie, 1986; Ball et al., 2002; Dahlin et al., 2009) while other reports showed also transfer effects to non-trained functions (e.g., Gopher et al., 1994; Klingberg et al., 2005; Willis et al., 2006; Ball et al., 2007; Caserta et al., 2007; Basak et al., 2008; Cassavaugh and Kramer, 2009; Edwards et al., 2009; Karbach and Kray, 2009; Klusmann et al., 2010; Jaeggi et al., 2011). As claimed by Kramer and Morrow (in press) and Hertzog et al. (2008) it may be important to design cognitive training interventions that are not limited to a single process (such as reasoning or processing speed) but instead incorporate a number of processes in the training program in order to maximize the general training gains. Accordingly, such a multidomain cognitive training may enhance the probability to observe transfer effects to non-trained or even daily life functions.

Multidomain training also provides novelty, which most likely stimulates brain plasticity (Düzel et al., 2010). Finally, multidomain training avoids monotony and enhances fun and the motivation to train. Hence it appears promising to conduct a multidomain training that involves several fluid functions in order to reach a cross-functional effect and elevate the probability for transfer to other areas or even to daily life activities (Kramer and Morrow, in press). Such training can be a complex videogame (Basak et al., 2008) or a mixture of training tasks which altogether covers most fluid functions.

A third possibility for stimulating cognition is an interaction in a social group and new experiences in general, which are known to stimulate neuroprotective effects in animal and human studies (Kempermann et al., 1997; Hultsch et al., 1999; Frick and Fernandez, 2003; Singh-Manoux et al., 2003; Milgram et al., 2006; Bielak et al., 2007; Hertzog et al., 2009; Swaab and Bao, 2011). Thus, the influence of group interactions as such has to be controlled.

Longitudinal studies examining training-induced changes of neuronal activity underlying the performance changes are rather sparse. Most of them investigated effects of cardiovascular training (Colcombe et al., 2004; Voelcker-Rehage et al., 2011). To our knowledge, effects of a longitudinal cognitive training on neuroelectrical activity in elderly people have not yet been analyzed. However, it could be assumed that cognitive training reflects a form of learning and acquiring of expertise including changes of neuronal networks (Lustig et al., 2009). As has been shown repeatedly, new experiences or managing of unusual complex situations are accompanied by synaptic plasticity and neurogenesis (Milgram et al., 2006; Whitlock et al., 2006; Greenwood, 2007; Pereira et al., 2007; Greenwood and Parasuraman, 2010; Swaab and Bao, 2011). A number of studies investigating neuronal correlates of simple perceptual or memory training in humans showed changes in the volume of gray matter (Ilg et al., 2008), white matter (Takeuchi et al., 2010), and cerebral blood flow (Mozolic et al., 2010) but also in electrical brain activity (e.g., Reinke et al., 2003; Roche and O'Mara, 2003; Song et al., 2005; Tong et al., 2009). It is likely that these phenomena are not independent and reflect consequences of a number of neurobiological adaptation processes. Training inducing plastic brain changes can also be observed in advanced age (Jones et al., 2006; Greenwood, 2007; Greenwood and Parasuraman, 2010; Zehnder et al., 2009, for reviews).

\section{THE PRESENT STUDY}

As mentioned above, there is, to our knowledge, by now no longitudinal study that investigated changes in electrical brain activity due to cognitive and physical training in older subjects. Thus, the present study aims at investigating the impact of a multidomain physical and a multidomain cognitive training on fluid cognitive and brain functions relative to a relaxation group as well as a no-contact control group. The training-related neurocognitive changes were assessed by a PC-based task switching paradigm and associated electrophysiological parameters.

By using the task switching paradigm specific functions like maintaining, selecting, and switching between multiple task sets can be analyzed as a function of aging (Kramer et al., 1999; Kray and Lindenberger, 2000; Cepeda et al., 2001; De Jong, 2001; Mayr, 2001; Mayr and Liebscher, 2001; Meiran et al., 2001; Kray et al., 2004; Kray, 2006; West and Travers, 2008). The role of the response selection and monitoring system is to translate the goals into action and to control the outcome in order to prevent possible errors. This function is strongly loaded during task switching and even more in switch trials than in repeat trials (Gajewski et al., 2010a).

Crucial behavioral outcomes of the task switching paradigm are so called mixing costs, defined as the difference between non-switch trials in mixed and single task blocks and local switch costs, defined as a difference between performance in task switch trials and non-switch trials (Allport et al., 1994; Rogers and Monsell, 1995; Meiran, 1996). Mixing costs are assumed to represent retrieval and active maintenance of multiple task sets in memory, whereas local costs are rather attributed to proactive interference between previously and the currently relevant task (see Kiesel et al., 2010 for overview). Mixing costs are consistently found to be enhanced in older age, whereas local costs usually do not differ between younger and older participants (e.g., Kramer et al., 1999; Kray and Lindenberger, 2000; Cepeda et al., 2001; Mayr, 2001; Kray, 2006; Gajewski et al., 2010b).

Some studies investigated intraindividual variability in speed performance as it has been shown that the variability is a valid behavioral indicator of neuronal integrity, which is declined in age (Hultsch and MacDonald, 2004). Thus, beside reaction times and error rates we analyzed this parameter to obtain possible training-related decrease of intra-personal variability (Ram et al., 2005). 
Event-related potentials (ERPs) offer additional insights in the electrophysiological mechanisms underlying task switching. As ERPs have an excellent time resolution, there is the possibility to analyze each sub-process involved in task switching. In the present study we focused on controlled and executive processes in task switching, namely response selection and error detection. In particular, we analyzed response selection as reflected in the N2 (Ritter et al., 1979, 1982, 1983; Towey et al., 1980; Gajewski et al., 2008, 2010a, 2011) and error detection as reflected in the Ne or ERN (Falkenstein et al., 1991; Gehring et al., 1993; Band and Kok, 2000; Falkenstein et al., 2000, 2001; Kolev et al., 2005). In addition the P3b was analyzed as a classical measure of working memory resources or more generally the processing capacity (Donchin, 1981; Donchin and Coles, 1988; Kok, 2001; Polich, 2007; Gajewski et al., 2010b; Gajewski and Falkenstein, 2011b).

As it has been shown that electrophysiological brain activity is enhanced by short-term training in different domains, we assume that some of the functions reflected in the ERPs will also be improved by a long-term cognitive and/or physical training. Thus, the electrophysiological markers should help to differentiate which processes are changed due to training and which are not. In particular, we expect enhancement of processing capacity as reflected in the $\mathrm{P} 3 \mathrm{~b}$ and response selection as reflected in the N2. Moreover, a more efficient response selection may also improve error detection, which should be reflected in an increase of the error negativity $(\mathrm{Ne})$. Consequently, performance improvements on behavioral level should be apparent in lower mixing and/or switch costs, in speed and/or accuracy, as previously shown (Karbach and Kray, 2009). An additional performance parameter reflecting the efficiency of taskrelated processing is the intraindividual variability of reaction times. A reduced variability of speed is assumed to reflect an increased coherence of neuronal processing (Hultsch and MacDonald, 2004), which appears in a more precise timing of response selection.

Since cognitive stimulation may also be induced by social interactions within a group, we included in the design two control groups: a social control group without cognitive demands in the contents, and a passive control group without group contact. To this end, 152 participants were randomly assigned to one of four groups: physical training, cognitive training, relaxation training (social control), and passive control (no-contact) group. Participants were trained for 4 months, two times per week, and 90 min per session. The cognitive training group received a multidomain paper and pencil and PC-based training, which, however, did not include a task switching training. The cognitive training was combined from cheap or freely available training packages. The physical training group received a multidomain, circular cardiovascular, strength, and aerobic training. The relaxation group conducted easy stretching, relaxation exercises, and autogenic training that were cognitively non-demanding, while the passive control group did not receive any intervention but was simply measured with respect to cognitive functions at about the same time as the active groups. In summary, all three active groups received a multifaceted physical or cognitive or wellness training, while the no-contact group received no intervention.

\section{MATERIALS AND METHODS PARTICIPANTS}

Participants were recruited through a number of newspaper advertisements and flyers distributed in the city of Dortmund (Germany). Participants were included in the study after meeting some criteria inquired by a telephone interview. They should be 65 or older, physically and mentally fit, living independently and selfpaced (no nursing home), and having sufficient or corrected visual and auditory acuity. Exclusion criterions were: history of cardiovascular, psychiatric, neurological, motor or oncologic diseases, and psychopharmacologic or hormonal therapy. Moreover, participants were not included if they already did train physically (jogging, walking, swimming, dancing, fitness center) or cognitively (e.g., memory training) more than $1.5 \mathrm{~h}$ weekly. Finally, they were asked whether they planned some travels or other activities in the next 6 months that would avoid regular training participation. Four hundred sixty-seven telephone interviews were completed, 152 persons met the criteria and were included in the study. Eleven participants dropped out during the study. Consequently, 141 participants constituted the final sample (Table 1).

The participants received 100 Euro at the end of the study to compensate their travel expenses. The study was approved by the local ethics committee of the Leibniz association and its accordance with the declaration of Helsinki. The scope of the study was explained to all participants and they were given a written informed consent before any study protocol was commenced. The groups were comparable in all socio-demographic, cognitive, personality, and physical variables presented in Table $\mathbf{1}$ as no significant differences were found.

\section{TRAININGS}

Participants were randomly assigned to one of four groups: physical, cognitive, and relaxation training and a control group. Participants were trained for 4 months, two times per week and $90 \mathrm{~min}$ per session. All trainings were supervised by professional trainers.

Physical training consisted of cardiovascular, aerobic, and strength exercises which were done to the same amount within each session. The cardiovascular training was conducted using treadmills, bicycle ergometers, and cross trainers which included pulse meters in order to control the heart function permanently. The aerobic exercises consisted of a number of easy step and floor movement sequences. The muscular strength exercises were conducted using strength machines as a combination of eight different sets which were repeated in $3 \times 15$ series by performing oppose muscle contraction. These exercises aimed at strengthening skeletal muscles and increasing the metabolism. Intensity of the training units was continuously increased but regarded the individual capability of the participants.

The multidomain cognitive training included paper and pencil and PC-based exercises. In the first 4 weeks the "Mental Activation Training" (MAT; Lehrl et al., 1994) and sudoku were used. Additionally, in the first eight sessions participants without any PC-experience were made step by step familiar with the computer handling. In the following weeks, the participants exercised using selected commercial and non-commercial internet-based software. The difficulty level of the exercises was continuously adapted to the individual abilities of the participants. 
Table 1 | Socio-demographic characteristics of the whole sample and separated for each experimental (physical, cognitive) and control (relaxation, no-contact) group.

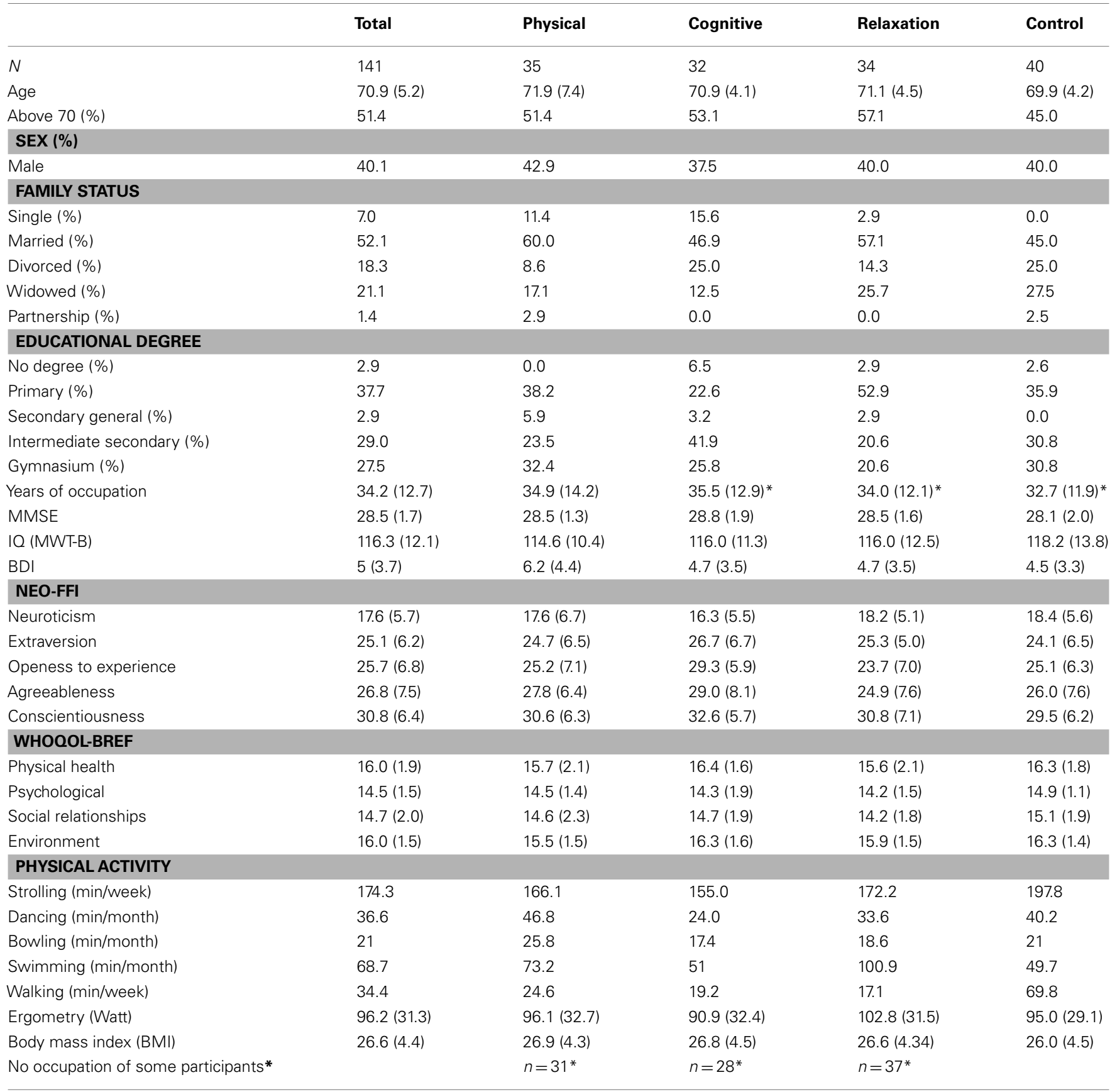

Distribution of some characteristics across the groups is presented in (\%), remaining values represent means and standard deviations in parentheses. Mini Mental State Examination (MMSE; Folstein et al., 1975), Multiple-choice vocabulary test (MWT-B; Lehrl et al., 1995), Becks Depression Inventory (BDI; Beck et al., 1961), WHO-Quality of Life-BREF WHOQOL Group, 1998), NEO-FFI ("Big Five" personality factors questionnaire; Costa and McCrae, 1992).

Each session consisted of different exercises that aimed at training crucial cognitive functions. The exercises mainly trained perceptual speed, attentional, and mnemonic functions but some exercises included reasoning or logical thinking. A detailed description of all used exercises and a schedule of the training program are given in the Appendix.
No explicit task switching exercise was included in this program. Two extra sessions were offered at the end of the program for those participants who missed the regular sessions. The participants were not encouraged to exercise outside the training sessions but to continue the training at home after the study was finished. 
The relaxation group received a relaxation training consisting of autogenic training, progressive muscle relaxation, back training, breathing exercises, massage, and Qigong. The aim of this training was to provide interesting and varied exercises, which did hardly require, and hence should not train, cognitive functions.

\section{TESTING}

Participants completed several questionnaires at home which they brought to the test session. During the testing a number of paper and pencil and computerized psychometric tasks were applied.

\section{STIMULI AND TASKS}

Stimuli consisted of the digits $1-9$, excluding the number 5 . The digits were white presented on a black computer screen $3 \mathrm{~mm}$ above the white fixation point (10 $\mathrm{mm}$ diameter). Each digit was either small $(7 \mathrm{~mm} \times 10 \mathrm{~mm})$ or large $(12 \mathrm{~mm} \times 18 \mathrm{~mm})$. A cue stimulus $(16 \mathrm{~mm} \times 32 \mathrm{~mm})$ indicating the relevant task was presented $3 \mathrm{~mm}$ below the fixation point. The cue "NUM" (German "Numerisch," numeric) indicated a numerical task (greater or less than 5), "GER" (German "Geradzahligkeit," parity) the parity task (odd vs. even), "SCH" (German "Schrift," font) the font-size task (small vs. large).

Responses consisted of pressing one of two buttons which were mounted in a response box. The buttons should be pressed with the index fingers.

The stimulus-response mapping of the three tasks was overlapping, that is, responses according to "smaller than five," "even," and "small size" were assigned to the left key and "larger than five," "odd," and "large size" to the right key. This assignment was counterbalanced across participants.

\section{PROCEDURE}

A schematic example of a trial is shown in Figure 1.

A trial started with a presentation of the fixation point. A cue stimulus that indicated the relevant task in advance was presented for $1300 \mathrm{~ms}$ which remained visible when the digit was presented. A response had to be given within $2500 \mathrm{~ms}$ after target onset. Five hundred milliseconds after the response a feedback was displayed for $500 \mathrm{~ms}$. In case of a correct response a plus sign, after a wrong response a minus sign was displayed. The response-cue interval (RCI) was set to $1000 \mathrm{~ms}$ and included the response-feedback delay and the feedback.

At the beginning of the session participants performed three single task blocks with a fixed task NUM, GER, and SCH consisting of 34 trials each. Afterward, the participants performed an exercise block with 16 trials including all three tasks, followed by the mixed block (124 trials). The frequency of task switch in the

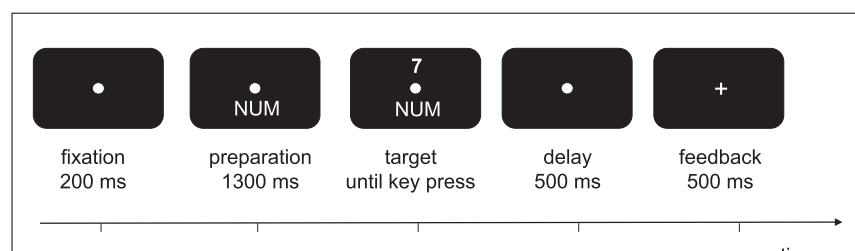

time

FIGURE 1 | Schematic illustration of a trial. cue-based block amounted to $50 \%$. The order of the trials was random. The participants were given a written instruction that explained the task. The instruction encouraged quick and accurate responses.

\section{ERP RECORDINGS}

EEG was recorded continuously from 32 scalp electrodes according to the extended 10-20 system (Jasper, 1958) and mounted on an elastic cap. The montage included 8 midline sites and 12 sites on each hemisphere and two mastoid electrodes (M1 and M2). The EEG was re-referenced offline to linked mastoids. The horizontal and vertical EOG was recorded bipolarly from electrodes at both eyes. Eye movement artifacts were corrected using the correction algorithm of Gratton et al. (1983). Electrode impedance was kept below $10 \mathrm{k} \Omega$. The amplifier bandpass was $0.01-140 \mathrm{~Hz}$. EEG and EOG were sampled continuously with a rate of $2048 \mathrm{~Hz}$. Offline, the EEG was downscaled to a sampling rate of $1000 \mathrm{~Hz}$ and cut in stimulus-locked epochs by using the software Vision Analyzer (Brain Products, Munich). Epochs in which the amplitude exceeded $\pm 150 \mu \mathrm{V}$ were rejected. The ERPs were filtered digitally offline with a $17 \mathrm{~Hz}$ low and $0.05 \mathrm{~Hz}$ high pass.

\section{DATA ANALYSIS}

The first trial of each test block, trials with responses faster than $100 \mathrm{~ms}$ or slower than $2500 \mathrm{~ms}$, as well as error trials, were excluded from the RT analysis. Mean RTs, standard deviations of RTs as an index of intraindividual variability of speed (ISDs) and mean error rates were subjected to two ANOVA designs assessing mixing and local effects. The first design included two within-subject factors BLOCK (single, mixed), SESSION (pre-measure: $t 1$ vs. post-measure: $t 2$ ) and the between-subject factor GROUP (physical, cognitive, relaxation, control). The second design included the factors TASK SET TRANSITION (non-switch, switch), SESSION ( $t 1$ vs. $t 2$ ) and the between-subject factor GROUP (physical, cognitive, relaxation, control).

Mixing costs were computed by subtracting mean performance of the single task blocks from the performance in non-switch trials of the mixed block. Local switch costs were computed by subtracting non-switch from switch trials of the mixed block.

In case of a significant interaction, a follow-up analysis was conducted. In the next step difference scores $(t 2-t 1)$ were computed and a pre-specified $a$ priori contrasts were conducted on those differences to determine group effects in training-induced improvements. To this end, we contrasted (1) the control group against the other three groups, (2) the physical and cognitive training groups against the relaxation group, (3) the physical against the cognitive group, (4) the physical against the relaxation group, (5) the cognitive against the relaxation group, (6) the physical against the no-contact group, and (7) the cognitive against the no-contact group. Note the $t$-values can be either negative or positive depending on a specific difference between the $t 2$ and $t 1$ scores which are usually negative due to shorter RTs and lower error rates at $t 2$ than at $t 1$.

The ERP analysis was restricted to the midline electrodes (FCz, $\mathrm{Cz}, \mathrm{CPz}$, and $\mathrm{Pz}$ ) as the $\mathrm{N} 2, \mathrm{P} 3 \mathrm{~b}$, and $\mathrm{Ne}$ are usually maximum at these electrodes. 
Peak amplitudes and latencies of transient components were measured at their local maximal or minimal amplitudes in predefined time windows. In the target-locked ERPs the N2 was measured as the most negative peak at $\mathrm{FCz}$ and $\mathrm{Cz}$ in the time range $200-400 \mathrm{~ms}$ after target onset. The $\mathrm{P} 3 \mathrm{~b}$ was measured as the most positive peak at $\mathrm{CPz}$ and $\mathrm{Pz}$ in the time range $300-600 \mathrm{~ms}$ after target onset. These post target ERPs were measured relative to $100 \mathrm{~ms}$ pre-target baseline. The error negativity (Ne/ERN) and the correct response negativity $(\mathrm{Nc} / \mathrm{CRN})$ were measured at $\mathrm{FCz}$ in the time range of $0-200 \mathrm{~ms}$ after an incorrect resp. correct response relative to $100 \mathrm{~ms}$ pre-response interval. The Ne and Nc were analyzed in the mixed block pooled for both types of task set transition (non-switch vs. switch).

The ERP analysis of mixing effects included following factors: BLOCK (single, mixed), SESSION $(t 1, t 2)$, GROUP (physical, cognitive, relaxation, control), and ELECTRODE. Local effects were analyzed by including following factors TASK SET TRANSITION (non-switch, switch), SESSION, GROUP, and ELECTRODE. In each of the omnibus ANOVAs conducted for each ERP parameter we included the factor ELECTRODE and reported the topographical results only when a significant interaction with mixing or local effects occurred. Otherwise, the most negative or positive amplitude of components reached at a particular electrode position, confirmed by a significant effect of ELECTRODE, indicated the site at which the follow-up analysis was conducted. Similarly to the follow-up analysis of behavioral data, we analyzed the above-mentioned pre-defined contrasts.

\section{RESULTS \\ BEHAVIORAL DATA \\ Reaction times}

Table 2 presents the mean reaction times, error rates, and intraindividual variability expressed in standard deviation for all groups and both sessions. Figure 2 shows mixing costs (nonswitch-single task), and local costs (switch-non-switch) in speed, intraindividual variability of speed and accuracy.

For the analysis of response times, error trials (10.2\%) and outliers $(5.8 \%)$ were discarded.

ANOVA assessing mixing effects in mean RTs revealed a main effect of SESSION $\left[F(1,137)=27.5, p<0.001, \eta^{2}=0.167\right]$, suggesting faster responses at $t 2(771 \mathrm{~ms})$ than $t 1(814 \mathrm{~ms})$ across all groups. There were reliable mixing costs, resulting from a main effect of BLOCK $\left[F(1,137)=574.9, p<0.001, \eta^{2}=0.808\right]$ with longer RTs in non-switch trials in the mixed than in the single task block (956 vs. $628 \mathrm{~ms}$ ). Moreover, SESSION interacted with BLOCK $\left[F(1,137)=17.1, p<0.001, \eta^{2}=0.111\right]$, showing reduced mixing costs at $t 2(300 \mathrm{~ms})$ compared to $t 1(356 \mathrm{~ms})$. There were no main effect or interactions including the factor GROUP in RTs (all Fs $<1$ ). No significant contrasts were found.

Analysis of the intraindividual variability of speed indexed by standard deviations showed a significant effect of SESSION $\left[F(1,137)=22.9, p<0.001, \eta^{2}=0.143\right]$, indicating reduced SDs at $t 2(262 \mathrm{~ms})$ relative to $t 1(282 \mathrm{~ms})$, an effect of BLOCK $\left[F(1,137)=1376.1, p<0.001, \eta^{2}=0.909\right]$, suggesting considerably higher SDs in mixed than single task block (392 vs. $153 \mathrm{~ms}$ ). Furthermore, there was an interaction SESSION $\times$ GROUP $[F(3$, $\left.137)=5.1, p<0.005, \eta^{2}=0.102\right]$ as well as a strong trend for
Table 2 | Mean reaction times, error rates and individual standard deviations (with standard deviations in parentheses) for single, non-switch and switch trials for the pre- and postmeasure for each group.

\begin{tabular}{|c|c|c|c|c|}
\hline & Physical & Cognitive & Relaxation & Control \\
\hline \multicolumn{5}{|c|}{ REACTION TIMES (ms) } \\
\hline \multicolumn{5}{|l|}{ Pretest } \\
\hline Single task & $642(88)$ & $622(81)$ & $639(96)$ & $637(94)$ \\
\hline Non-switch & $1025(264)$ & $984(210)$ & $1010(182)$ & $951(244$ \\
\hline Switch & $1205(310)$ & $1107(230)$ & $1135(222)$ & $1058(285)$ \\
\hline \multicolumn{5}{|l|}{ Posttest } \\
\hline Single task & $627(79)$ & $600(116)$ & $632(111)$ & $623(101)$ \\
\hline Non-switch & $959(217)$ & $873(253)$ & $938(207)$ & $912(257)$ \\
\hline Switch & $1071(276)$ & $964(283)$ & $1033(262)$ & $1000(287)$ \\
\hline \multicolumn{5}{|c|}{ INDIVIDUAL STANDARD DEVIATIONS (ms) } \\
\hline \multicolumn{5}{|l|}{ Pretest } \\
\hline Single task & $149(42)$ & $162(55)$ & $164(62)$ & $153(51)$ \\
\hline Non-switch & $399(101)$ & $431(88)$ & $412(88)$ & 395 (113) \\
\hline Switch & 466 (103) & 469 (104) & $458(88)$ & 420 (119) \\
\hline \multicolumn{5}{|l|}{ Posttest } \\
\hline Single task & 149 (35) & 142 (59) & $158(56)$ & $148(50)$ \\
\hline Non-switch & $394(87)$ & $348(101)$ & $385(75)$ & $371(101)$ \\
\hline Switch & $426(104)$ & $393(115)$ & $403(104)$ & $386(112)$ \\
\hline \multicolumn{5}{|c|}{ ERROR RATES (\%) } \\
\hline \multicolumn{5}{|l|}{ Pretest } \\
\hline Single task & $1.2(1.4)$ & $2.6(2.7)$ & $2.5(2.2)$ & $2.9(5.7)$ \\
\hline Non-switch & $18.1(12.6)$ & $17.4(14.2)$ & $18.4(13.1)$ & $13.0(11.3)$ \\
\hline Switch & $21.0(18.5)$ & $19.5(18.5)$ & $20.7(14.2)$ & $15.6(11.8)$ \\
\hline \multicolumn{5}{|l|}{ Posttest } \\
\hline Single task & $1.2(1.4)$ & $1.9(1.7)$ & $2.6(4.8)$ & $2.5(3.4)$ \\
\hline Non-switch & $13.8(12.1)$ & $8.5(10.1)$ & $12.6(10.8)$ & $13.2(12.8)$ \\
\hline Switch & $16.8(17.4)$ & $10.0(13.7)$ & $14.5(12.3)$ & $14.7(15.1)$ \\
\hline
\end{tabular}

a SESSION $\times$ GROUP $\times$ BLOCK interaction $[F(3,137)=2.7$, $\left.p=0.054, \eta^{2}=0.054\right]$. In order to resolve these interactions effects of SESSION and BLOCK were investigated for each group separately. A reliable main effect of SESSION was found in the cognitive group only $\left[F(1,31)=20.1, p<0.001, \eta^{2}=0.393\right]$, indicating reduced RT-variability after cognitive training. Moreover, the interaction SESSION $\times \operatorname{BLOCK}[F(1,31)=12.6, p<0.001$, $\left.\eta^{2}=0.290\right]$ suggested that this reduction was mainly due to the mixed (431 vs. $348 \mathrm{~ms}, F(1,31)=20.8, p<0.001, \eta^{2}=0.402$ ) rather than the single task block [162 vs. $142 \mathrm{~ms}, F(1,31)=4.2$, $\left.p<0.05, \eta^{2}=0.120\right]$. No significant reduction of intraindividual variability was found in the remaining groups.

Finally, a priori contrasts revealed a reduction of intraindividual variability in speed between $t 1$ and $t 2$ in the cognitive relative to physical $[t(137)=-2.65, p<0.01]$, no-contact $[t(137)=2.10, p<0.05]$ and tendentially relative to the relaxation group $[t(137)=1.92, p=0.057]$.

Regarding local effects, ANOVA yielded a main effect of TASK SET TRANSITION $\left[F(1,137)=218.6, p<0.001, \eta^{2}=0.615\right]$, reflecting reliable local switch costs in mean RTs (956 vs. $1072 \mathrm{ms,}$ for non-switch and switch trials, respectively) and a main effect of SESSION $\left[F(1,137)=33.0, p<0.001, \eta^{2}=0.194\right]$, indicating 
pretest 2 posttest
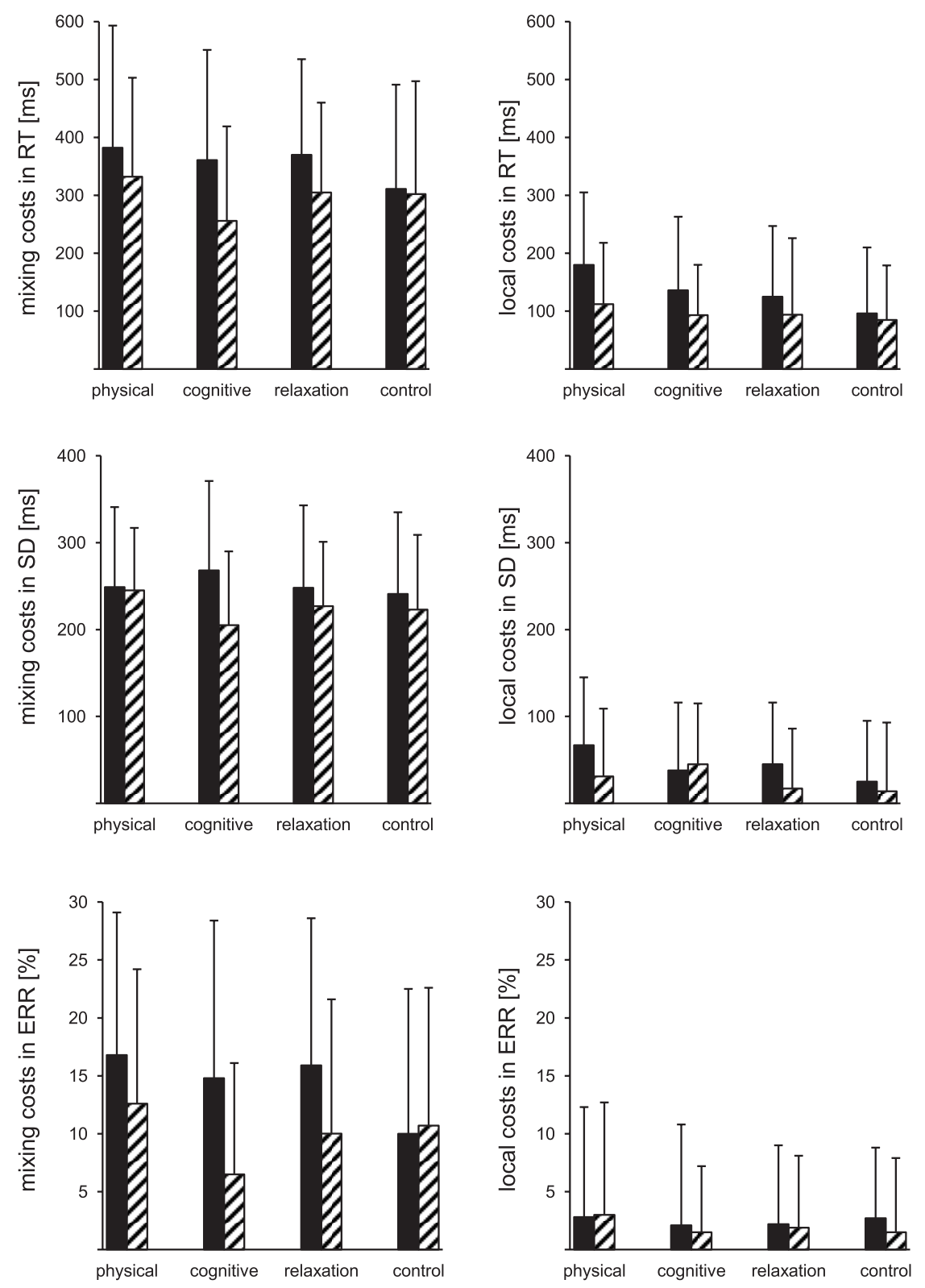

FIGURE 2 | Mixing costs (left) and local costs (right) expressed as the mean reaction times (RT), mean standard deviations (SD), and mean error rates (ERR) for pre- and post-test and each group. The error bars reflect standard deviation.

reduced RTs at $t 2(969 \mathrm{~ms})$ relative to $t 1(1059 \mathrm{~ms})$. Moreover, local switch costs were smaller at $t 2$ than $t 1$ as reflected in an interaction TASK SET TRANSITION $\times$ SESSION $[F(1,137)=10.4$, $\left.p<0.005, \eta^{2}=0.078\right]$. However, no main effect of GROUP $[F(1$, $137)=1.3, p=0.33]$ nor interactions with GROUP were found.

Analysis of the SDs yielded a main effect of TASK SET TRANSITION $\left[F(1,137)=59.6, p<0.001, \eta^{2}=0.303\right]$, suggesting higher variability in task switch than non-switch trials (428 vs. $392 \mathrm{~ms}$ ) and a main effect of SESSION $[F(1,137)=36.9$, $\left.p<0.001, \eta^{2}=0.212\right]$ due to a variability reduction from $t 1$ to t2 (431 vs. $388 \mathrm{~ms}$ ). Furthermore, there was a trend for a reduction of local costs in SDs from $44 \mathrm{~ms}$ in $t 1$ to $27 \mathrm{~ms}$ in $t 2[F(1$, $\left.137)=3.9, p=0.051, \eta^{2}=0.027\right]$. Finally, there was an interaction SESSION $\times$ GROUP $\left[F(3,137)=3.1, p<0.05, \eta^{2}=0.062\right]$, indicating a reduction of the SD from $t 1$ to $t 2$ in the cognitive [ 450 vs. $\left.370 \mathrm{~ms} ; F(1,31)=21.3, p<0.001, \eta^{2}=0.432\right]$, relaxation [ 435 vs. $\left.394 \mathrm{~ms} ; F(1,33)=8.5, p<0.01, \eta^{2}=0.205\right]$, and no-contact [408 vs. $\left.378 \mathrm{~ms} ; F(1,39)=5.8, p<0.05, \eta^{2}=0.131\right]$ but not 
in the physical group [ 433 vs. $410 \mathrm{~ms} ; F(1,34)=2.7, p=0.10$, $\left.\eta^{2}=0.076\right]$. However, the planned contrasts revealed no significant local effects, suggesting a similar reduction of intraindividual variability between $t 1$ and $t 2$ in speed in all groups.

\section{Error rates}

Analysis of mixing effects in mean error rates yielded a main effect of BLOCK $\left[F(1,137)=182.0, p<0.001, \eta^{2}=0.571\right]$ with higher error rates in the mixing $(14.4 \%)$ than in the single task block $(2.2 \%)$. The error rates were generally reduced from pre- to post-measure resulting in a main effect of SESSION $\left[F(1,137)=26.4, p<0.001, \eta^{2}=0.162\right]$. BLOCK and SESSION interacted significantly $[F(1,137)=21.5, p<0.001$, $\left.\eta^{2}=0.136\right]$, suggesting reduced mixing costs in accuracy at t2 (2.0 and $12.0 \%)$ relative to $t 1$ (2.3 and $16.7 \%$, for single task and non-switch trials, respectively). No main effect of GROUP was found $[F(1,137)<1]$. However, significant interactions SESSION $\times$ GROUP $\left[F(3,137)=4.1, p<0.01, \eta^{2}=0.082\right]$ and BLOCK $\times$ SESSION $\times$ GROUP $[F(3,137)=4.2, p<0.01$, $\left.\eta^{2}=0.084\right]$ were found. To resolve this result pattern the BLOCK $\times$ SESSION interaction was analyzed for each group separately. The physical group reduced their errors from $t 1$ to $t 2$ [9.7 vs. $\left.7.5 \% ; F(1,34)=8.8, p<0.01, \eta^{2}=0.205\right]$. This reduction was larger in the mixed (18.1 vs. $13.8 \%$ ) than the single task block (1.3 vs. $1.2 \%)$, resulting in an interaction of both factors $\left[F(1,34)=8.6, p<0.01, \eta^{2}=0.202\right]$. Similarly, the cognitive training group reduced their errors rates from $10.1 \%$ before to $5.2 \%$ after the training $\left[F(1,31)=18.9, p<0.001, \eta^{2}=0.379\right]$. This reduction was again larger in the mixed ( 17.5 vs. $8.5 \%)$ than in the single task block (2.6 vs. $2.0 \%$ ), as shown in an interaction BLOCK $\times$ SESSION $\left[F(1,31)=11.9, p<0.005, \eta^{2}=0.277\right]$. The relaxation group also improved accuracy from $t 1$ to $t 2[10.5$ vs. $\left.7.6 \% ; F(1,33)=7.1, p<0.05, \eta^{2}=0.178\right]$ in mixed (18.4 vs. $12.6 \%)$ but not in the single task block $(2.5$ vs. $2.7 \%)$ as indicated by the interaction BLOCK $\times$ SESSION $[F(1,33)=7.5, p<0.01$, $\left.\eta^{2}=0.186\right]$. In contrast, no changes from $t 1$ to $t 2$ were observed in the no-contact group (both $F s<1$ ).

A priori contrasts showed that the three training groups reduced mixing costs in accuracy more than the no-contact group $[t(137)=3.25, p<0.001]$. There was also a trend for a reduction of mixing costs after the physical and cognitive trainings relative to the relaxation training $[t(137)=1.90, p=0.059]$ and a clear reduction of mixing costs after cognitive training relative to the no-contact group $[t(137)=3.35, p<0.001]$. The contrast between the physical and cognitive group did not reach significance $[t(137)=-1.46, p=0.146]$.

Regarding local effects, ANOVA revealed an effect of TASK SET TRANSITION by higher error rates in task switch than non-switch trials $\left[16.6\right.$ vs. $\left.14.4 \% ; F(1,137)=17.9, p<0.001, \eta^{2}=0.116\right]$. These costs did not vary as a function of SESSION or GROUP. A main effect of SESSION $\left[F(1,137)=27.2, p<0.001, \eta^{2}=0.165\right]$ indicated lower error rates at $t 2$ than $t 1(13.0$ vs. $18.0 \%)$. Moreover, SESSION interacted with GROUP $[F(3,137)=3.9, p<0.01$, $\left.\eta^{2}=0.079\right]$. Analyses conducted for each group separately showed effect of SESSION only, i.e., reduction of error rates between $t 1$ und $t 2$ in the physical [ 19.5 vs. $15.3 \% ; F(1,34)=5.5, p<0.05$, $\left.\eta^{2}=0.141\right]$, cognitive [18.5 vs. $9.3 \% ; F(1,31)=12.0, p<0.005$, $\left.\eta^{2}=0.279\right]$ and relaxation group [ 19.5 vs. $13.6 \% ; F(1,33)=10.7$, $\left.p<0.005, \eta^{2}=0.245\right]$, whereas, again no effect was found in the no-contact group $(F<1)$.

The contrasts confirmed the reduction of error rates in the three training groups relative to the no-contact group in nonswitch $[t(137)=3.37, p<0.001]$ and switch trials $[t(137)=2.26$, $p<0.05]$ and a stronger reduction of error rates in the physical and cognitive groups than in the relaxation and no-contact groups for non-switch trials $[t(137)=2.16, p<0.05]$. Finally, cognitive training group improved the accuracy relative to the no-contact group both in non-switch $[t(137)=3.69, p<0.001]$ and switch trials $[t(137)=2.70, p<0.01]$.

In summary, mixing costs in mean RTs were not differently reduced between the groups from pre to post session. However, intraindividual variability of speed was reliably reduced after cognitive training relative to the other groups. Mixing costs in accuracy were reduced in the three training groups relative to the no-contact group, but the difference to the no-contact group was only significant for the cognitive training group. There were no group specific effects of local costs in reaction times and intraindividual RT-variability. However, the three training groups enhanced the accuracy after training but a reliable improvement relative to the no-contact group was again found for the cognitive training group only.

\section{ERP DATA}

Target-locked ERPs are showed in Figure 3. In the task implementation phase the $\mathrm{N} 2$ and $\mathrm{P} 3 \mathrm{~b}$ were analyzed. The peak amplitudes of N2 and P3b are depicted in Figures 4 and 5.

\section{N2}

\section{Mixing effects}

The N2 was analyzed as a function of BLOCK (single, mixed), SESSION $(t 1, t 2)$, GROUP, and ELECTRODE (FCz, Cz). The ANOVA revealed a main effect of BLOCK $[F(1,137)=66.01$, $\left.p<0.001, \eta^{2}=0.325\right]$, suggesting a more pronounced $\mathrm{N} 2$ in the single $(-0.8 \mu \mathrm{V})$ than in the non-switch trials of the mixed block $(0.6 \mu \mathrm{V})$ and a main effect of ELECTRODE $[F(1,137)=34.24$, $\left.p<0.001, \eta^{2}=0.200\right]$ that was due to a more negative $\mathrm{N} 2$ at $\mathrm{Cz}$ $(-0.4 \mu \mathrm{V})$ than $\mathrm{FCz}(0.2 \mu \mathrm{V})$. No effects or interactions including SESSION or GROUP factors were found.

\section{Local effects}

ANOVA yielded a significant main effect ELECTRODE $[F(1$, $\left.137)=20.80, p<0.001, \eta^{2}=0.132\right]$ indicating again a more pronounced $\mathrm{N} 2$ at $\mathrm{Cz}(0.4 \mu \mathrm{V})$ than $\mathrm{FCz}(0.9 \mu \mathrm{V})$. Importantly, there was an interaction SESSION $\times$ GROUP $[F(1,137)=2.98$, $\left.p<0.05, \eta^{2}=0.061\right]$ and SESSION $\times$ GROUP $\times$ ELECTRODE $\left[F(1,137)=3.87, p<0.01, \eta^{2}=0.078\right]$. In order to resolve this interaction follow-up analyses were conducted for each electrode separately. For $\mathrm{FCz}$ no effects or interaction were found. However, at $\mathrm{Cz}$ the $\mathrm{N} 2$ was more negative at $t 2(0.2 \mu \mathrm{V})$ relative to $t 1(0.6 \mu \mathrm{V})$ resulting in an effect of SESSION [ $F(1$, $\left.137)=4.72, p<0.05, \eta^{2}=0.033\right)$. Moreover, SESSION interacted with GROUP $\left[F(3,137)=4.82, p<0.005, \eta^{2}=0.096\right]$. This pattern indicated a more negative $\mathrm{N} 2$ in the cognitive group after the training than before $[-0.8$ vs. $0.3 \mu \mathrm{V} ; F(1,31)=9.18, p<0.005$, 


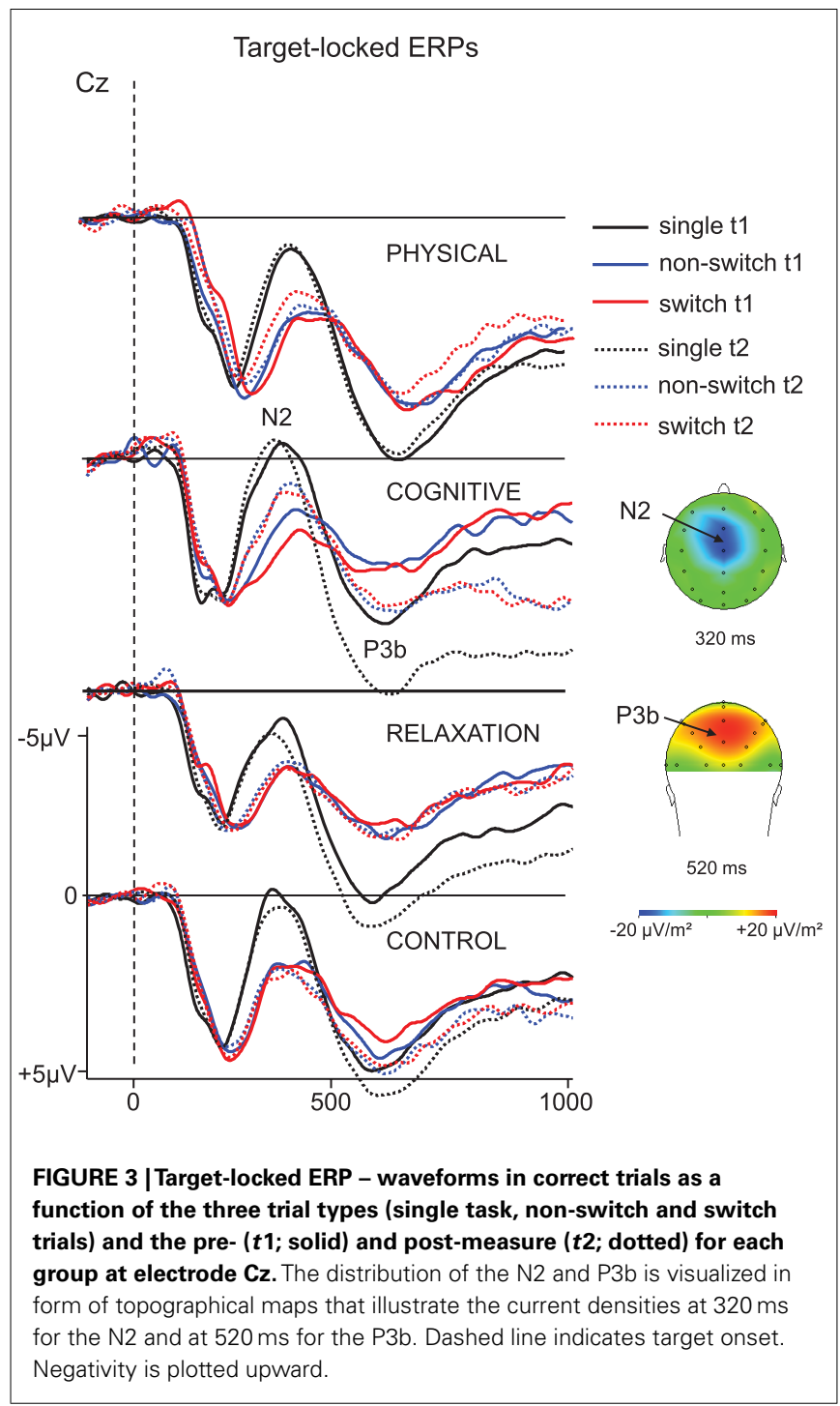

$\left.\eta^{2}=0.229\right]$ whereas no effect of SESSION was obtained in the other training groups (all $F \mathrm{~s}<1$ ). The no-contact group even showed a opposite pattern, i.e., a less negative $\mathrm{N} 2$ at $t 2$ than $t 1$ [ 0.6 vs. $\left.0.1 \mu \mathrm{V} ; F(1,39)=5.00, p<0.05, \eta^{2}=0.114\right]$. The N2-effect in the cognitive training group was only tendentially significant in the non-switch trials $[0.0$ vs. $-0.8 \mu \mathrm{V} ; F(1,31)=3.55, p=0.06$, $\left.\eta^{2}=0.103\right]$ while there was a highly significant $\mathrm{N} 2$ enhancement in the switch trials [0.6 vs. $-0.8 \mu \mathrm{V} ; F(1,31)=12.59, p<0.001$, $\left.\eta^{2}=0.289\right]$, for $t 1$ and $t 2$, respectively.

For non-switch trials, the contrasts conducted for the difference $t 2-t 1$ at $\mathrm{Cz}$ revealed an $\mathrm{N} 2$ increase in all training groups vs. the no-contact group $[t(137)=1.98, p<0.05]$ and an increase of the cognitive vs. the no-contact group $[t(137)=2.15, p<0.05]$. In task switch trials the contrast between all training groups and the no-contact group was also significant $[t(137)=3.38, p<0.001]$ as well the contrast between the physical and cognitive groups versus the relaxation and no-contact groups $[t(137)=3.39, p<0.001]$ due to higher N2 in the training groups. Finally, the N2 after cognitive training was reliably enhanced relative to the relaxation group $[t(137)=2.35, p<0.05]$ and the no-contact group $[t(137)=4.02$, $p<0.001]$. The contrast between physical and cognitive group did not reach significance $[t(137)=-1.59, p=0.11]$.

Summarizing, the $\mathrm{N} 2$ was substantially increased after cognitive training primarily in task switch trials. Between-group contrasts supported the $\mathrm{N} 2$ increase in the cognitive group relative to the relaxation and no-contact groups.

\section{P3b \\ Mixing effects}

For the $\mathrm{P} 3 \mathrm{~b}$ measured at $\mathrm{CPz}$ and $\mathrm{Pz}$ the ANOVA showed a main effect of BLOCK $\left[F(1,137)=187.83, p<0.001, \eta^{2}=0.578\right]$ which resulted in a substantially larger $\mathrm{P} 3 \mathrm{~b}$ in the single than mixed block $(9.2$ vs. $6.3 \mu \mathrm{V})$ and an effect of SESSION, indicating higher amplitude at $t 2$ vs. $t 1(8.1$ vs. $7.4 \mu \mathrm{V}$; $\left.F(1,137)=14.44, p<0.001, \eta^{2}=0.095\right)$. Moreover, there was an interaction SESSION $\times$ GROUP $[F(3,137)=2.81, p<0.05$, $\left.\eta^{2}=0.058\right]$ and BLOCK $\times$ SESSION $\times$ GROUP $\times$ ELECTRODE $\left[F(3,137)=2.79, p<0.05, \eta^{2}=0.058\right]$. To resolve this pattern, we analyzed the effect of BLOCK, SESSION and ELECTRODE for each group separately. A main effect of SESSION $\left[F(1,31)=17.18, p<0.001, \eta^{2}=0.357\right]$ and an interaction BLOCK $\times$ SESSION $\times$ ELECTRODE $[F(3,31)=7.32, p<0.01$, $\left.\eta^{2}=0.191\right]$ were found for the cognitive group only. Investigating the electrodes separately, the effect of SESSION indicating increased $\mathrm{P} 3 \mathrm{~b}$ at $t 2$ vs. $t 1$ was significant at $\mathrm{CPz}$ (8.3 vs. $6.7 \mu \mathrm{V} ; F(1,31)=15.94, p<0.001, \eta^{2}=0.340$ and $\mathrm{Pz}$ (8.5 vs. $\left.7.1 \mu \mathrm{V} ; F(1,31)=14.32, p<0.001, \eta^{2}=0.317\right)$. No interaction $\mathrm{SESSION} \times \mathrm{BLOCK}$ was found. In other words, the P3b was enhanced after the cognitive training both in single task as well as non-switch trials of the mixed task block.

For single task blocks the planned comparisons for the $\mathrm{P} 3 \mathrm{~b}$ at $\mathrm{CPz}$ revealed a larger increase for the cognitive vs. the physical group $[t(137)=3.05, p<0.005]$, and tendentially for the cognitive vs. the relaxation group $[t(137)=-1.96, p=0.052]$ and the cognitive vs. the no-contact group $[t(137)=-1.84, p=0.067]$.

In the non-switch trials of the mixed block there was an slightly enhanced $\mathrm{P} 3 \mathrm{~b}$ in the cognitive group, indicated by the trend for the contrast cognitive vs. no-contact group $[t(137)=-1.87, p=0.063]$. This contrast reached significance at $\mathrm{Pz}[t(137)=-1.98, p<0.05]$. No further effects were obtained.

\section{LOCAL EFFECTS}

The ANOVA investigating the impact of training on the $\mathrm{P} 3 \mathrm{~b}$ as a function of local effects revealed an effect of SESSION $\left[F(1,137)=6.05, p<0.05, \eta^{2}=0.042\right]$ and an interaction SESSION $\times$ GROUP $\times$ TASK SET TRANSITION $\times$ ELECTRODE $\left[F(3,137)=2.77, p<0.05, \eta^{2}=0.057\right]$. To resolve this interaction, we firstly conducted ANOVAs for each electrode separately. At $\mathrm{CPz}$ again an effect of SESSION $[F(1,137)=6.29, p<0.05$, $\left.\eta^{2}=0.043\right]$ was found, suggesting generally slightly enhanced P3b at $t 2$ vs. $t 1(6.4$ vs. $5.9 \mu \mathrm{V})$. Moreover, an interaction SESSION $\times$ GROUP occurred $\left[F(3,137)=3.77, p<0.05, \eta^{2}=0.076\right]$ that implied a different pattern of the $\mathrm{P} 3 \mathrm{~b}$ in the four groups. At $\mathrm{Pz}$ no effects or interactions were found. Thus, in the next step ANOVAs were conducted for each group at $\mathrm{CPz}$ : for the physical group an interaction SESSION $\times$ TASK SET TRANSITION was significant 
pretest $\bigvee$ posttest
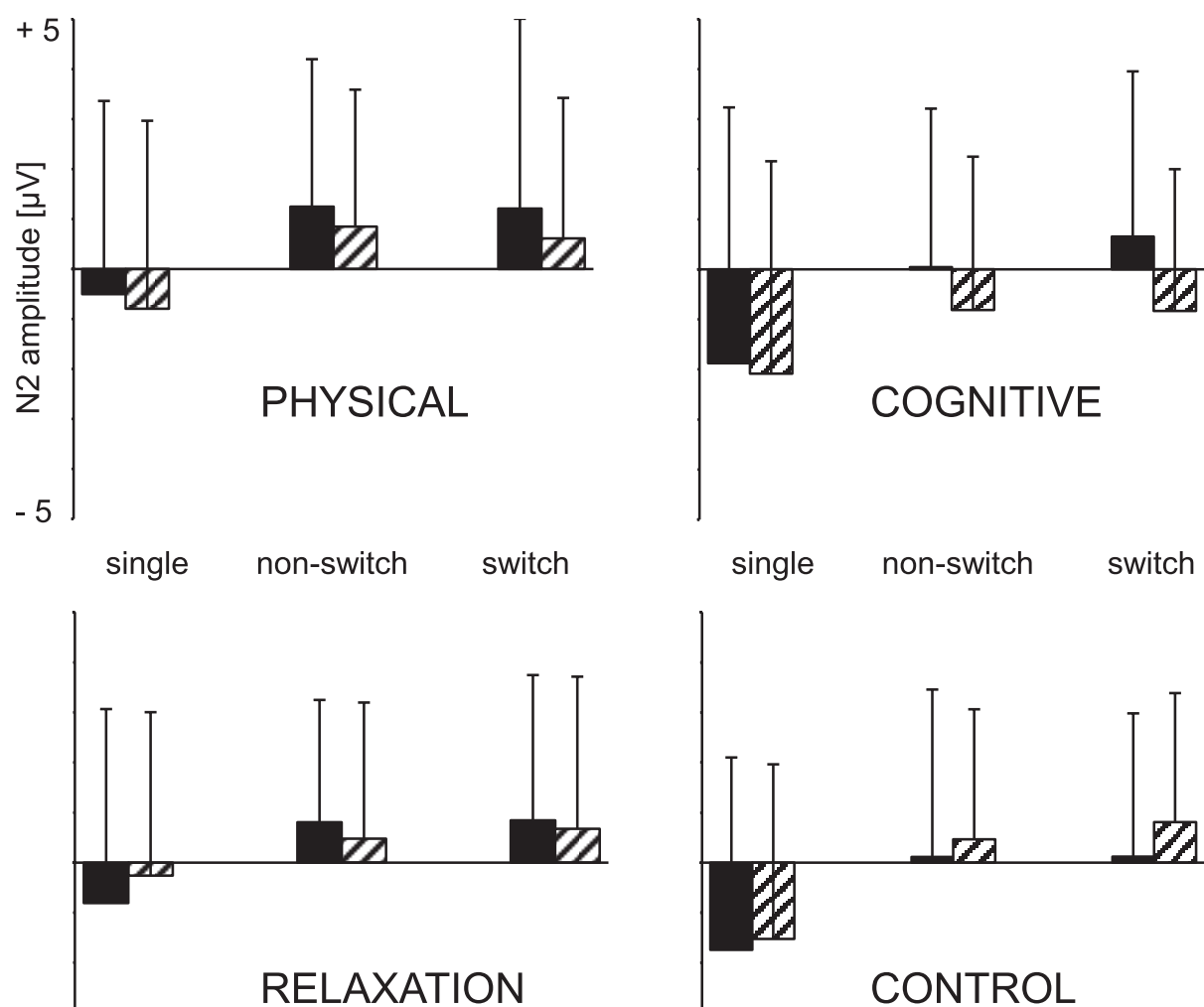

single non-switch switch

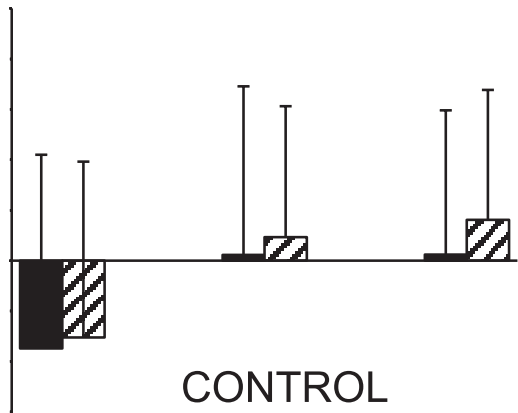

FIGURE 4 | Mean peak amplitudes of the N2 at Cz as a function of the trial type (single task, non-switch and switch trials), session (pre vs. post) and group. The error bars reflect standard deviation (SD).

$\left[F(1,34)=4.57, p<0.05, \eta^{2}=0.119\right]$, suggesting a reduction of the $\mathrm{P} 3 \mathrm{~b}$ in switch trials between $t 1$ and $t 2(7.1$ vs. $6.4 \mu \mathrm{V})$ and an unchanged amplitude in non-switch trials (6.8 vs. $6.4 \mu \mathrm{V})$. For the cognitive group there was a main effect of SESSION $[F(1$, $\left.31)=6.60, p<0.05, \eta^{2}=0.176\right]$ indicating a generally increased P3b after training $(5.3$ vs. $6.5 \mu \mathrm{V})$.

The contrasts conducted for switch trials of the mixed block at $\mathrm{CPz}$ revealed a $\mathrm{P} 3 \mathrm{~b}$ enhancement from $t 1$ to $t 2$ in the physical, cognitive and relaxation groups vs. the no-contact group $[t(137)=-1.97, p<0.05]$, a stronger amplitude increase in the cognitive than physical group $[t(137)=2.64, p<0.01]$ and a trend for larger $\mathrm{P} 3 \mathrm{~b}$ after training in the cognitive than in the relaxation group $[t(137)=-1.74, p=0.078]$.

In summary, the $\mathrm{P} 3 \mathrm{~b}$ was generally enhanced after cognitive training in both single task and mixed blocks. In the physical group a switch specific reduction of the $\mathrm{P} 3 \mathrm{~b}$ relative to non-switch trials was found after training.

\section{$\mathrm{Ne}$}

The response-locked ERPs for the error trials are depicted in Figure 6. The peak amplitude of the Ne collapsed across switch and non-switch trials is presented in Figure 7.
The analysis of the $\mathrm{Ne}$ at $\mathrm{FCz}$ for the mixed block revealed a main effect of SESSION $\left[F(1,137)=4.08, p<0.05, \eta^{2}=0.029\right]$ and an interaction SESSION $\times$ GROUP $[F(3,137)=4.45$, $\left.p<0.005, \eta^{2}=0.089\right]$. In the next step the effect of SESSION was analyzed for each group separately: an increase of the Ne amplitude between $t 1$ and $t 2$ was found in the cognitive group only $\left[-4.2\right.$ vs. $\left.-8.1 \mu \mathrm{V} ; F(1,31)=8.48, p<0.01, \eta^{2}=0.215\right]$.

Planned comparisons between the groups for the $t 2-t 1$ difference showed a substantially higher $\mathrm{Ne}$ in the cognitive training group for the contrasts: physical and cognitive vs. relaxation and no-contact group $[t(137)=2.03, p<0.05]$, physical and cognitive vs. relaxation group $[t(137)=-2.27, p<0.05]$ and for all individual contrasts between the cognitive group and the other groups: cognitive vs. physical $[t(137)=-2.91, p<0.005]$, cognitive vs. relaxation $[t(137)=2.38, p<0.05]$, and cognitive vs. no-contact group $[t(137)=3.39, p<0.001]$.

Nc

The analysis of the negative response-locked potential recorded in correct responses, the $\mathrm{Nc}$ measured at $\mathrm{FCz}$ revealed no effect of SESSION $\left[F(1,137)=2.85, p=0.09, \eta^{2}=0.020\right]$, GROUP and no interaction SESSION $\times$ GROUP $($ both $F s<1)$. 


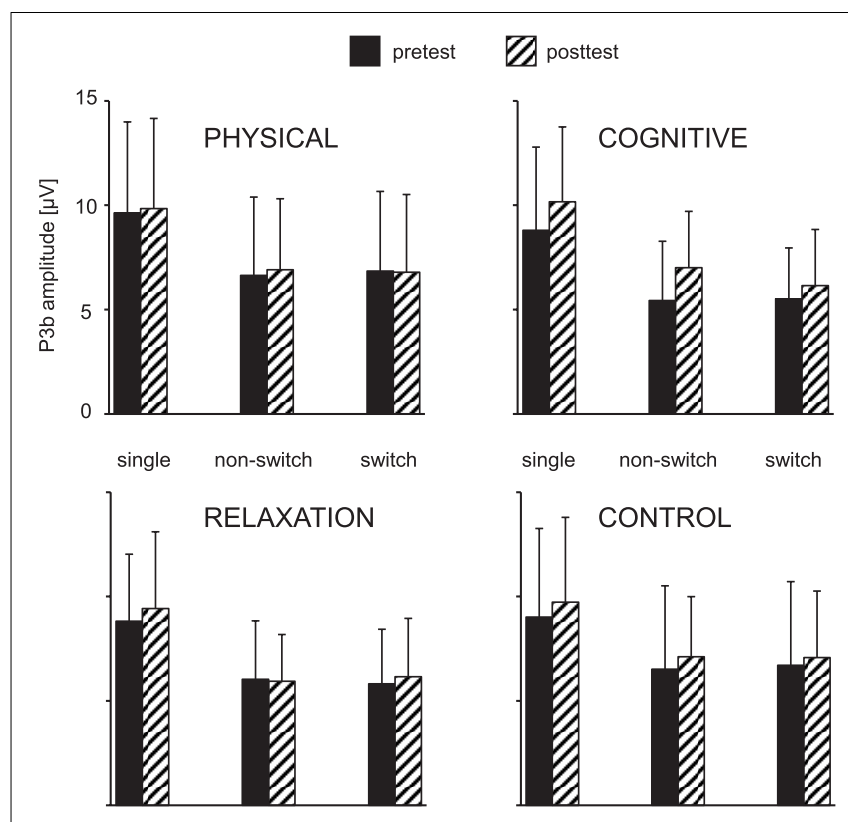

FIGURE 5 | Mean peak amplitudes of the P3b at Pz as a function of the trial type (single task, non-switch and switch trials), session (pre vs. post) and group. The error bars reflect standard deviation (SD).

In summary, error monitoring indexed by the Ne was strongly enhanced after cognitive training only, whereas no significant changes of the correct response negativity Nc were found.

\section{RELATIONSHIP BETWEEN ERP AND BEHAVIORAL RESULTS}

The N2 latency at $\mathrm{Cz}$ correlated with RTs in the corresponding conditions at $t 1$ in single $(r=0.33, p<0.001)$ and switch trials $(r=0.27, p<0.001)$. The correlations were more consistent at $t 2$ (single: $r=0.43, p<0.001$; non-switch: $r=0.39$, $p<0.001$; and switch trials: $r=0.33, p<0.001)$. Moreover, the $\mathrm{N} 2$ latency also correlated with error rates at $t 1$ in switch trials $(r=0.25, p<0.005)$ and again more consistently at $t 2$ (single: $r=0.16, p<0.05$; non-switch: $r=0.33, p<0.001$; and switch trials: $r=0.28, p<0.001)$.

The N2 latency vs. RT correlations were absent in the physical group but remained stable in the cognitive group at $t 1$ (single: $r=0.49, p<0.001$; non-switch: $r=0.35, p<0.05)$ and more consistently at $t 2$ (single: $r=0.54, p<0.001$; non-switch: $r=0.53$, $p<0.001$; and switch trials: $r=0.36, p<0.05)$. For the relaxation group for switch trials only at $t 1 \quad(r=0.57, p<0.001)$ and $t 2(r=0.35, p<0.05)$ and no-contact group at $t 1$ (single: $r=0.36, p<0.05$; non-switch: $r=0.47, p<0.005)$ and $t 2$ (single: $r=0.47, p<0.005$; non-switch: $r=0.41, p<0.01$; and switch trials: $r=0.51, p<0.001)$.

No correlations between the $\mathrm{N} 2$ amplitude and behavioral data were found.

The Ne amplitude at $t 2$ was moderately but significantly correlated with error rates across all groups $(r=0.20, p<0.05$ and $r=0.17, p<0.05$ ) for non-switch and switch trials, respectively. The Ne latency correlated positively with error rates in the switch trials only $(r=0.20, p<0.05)$.

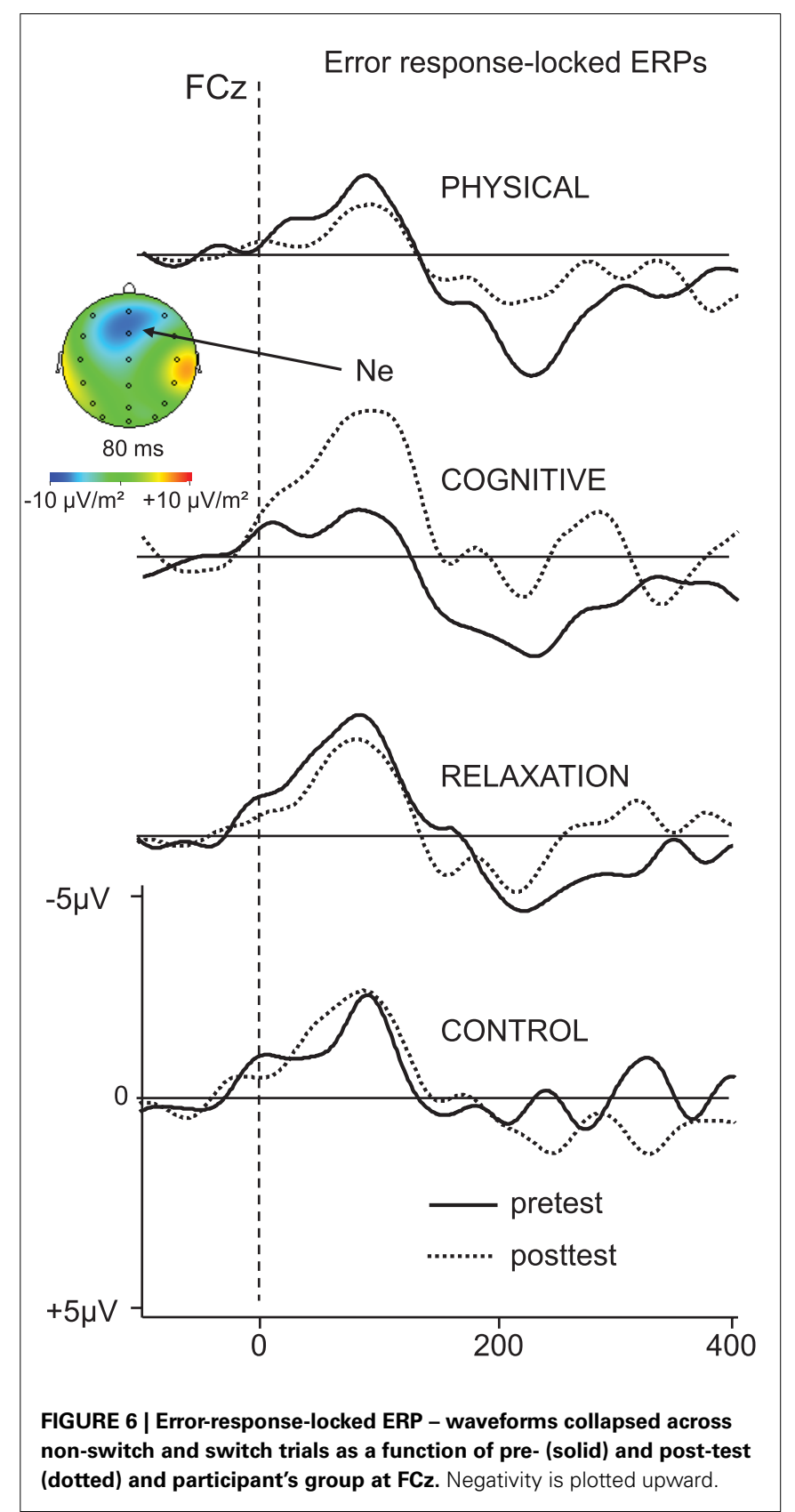

In summary, the N2 latency was consistently correlated with RTs and accuracy in the whole sample. This relationship remained stable primarily for the cognitive and non-contact group. The correlations were enhanced at $t 2$ relative to $t 1$. The $\mathrm{Ne}$ was moderately correlated with error rates in the whole sample.

\section{SUBJECTIVE EVALUATION OF TRAINING}

In order to assess the subjective benefit, fun, behavioral changes, and the motivation to continue the training individually, the participants filled in a self-made questionnaire after the training was finished. This also helped to evaluate the training motivation indirectly. For example, regarding the question "Did you like to participate in the training?" 97,92 , and $88 \%$ of the participants of 


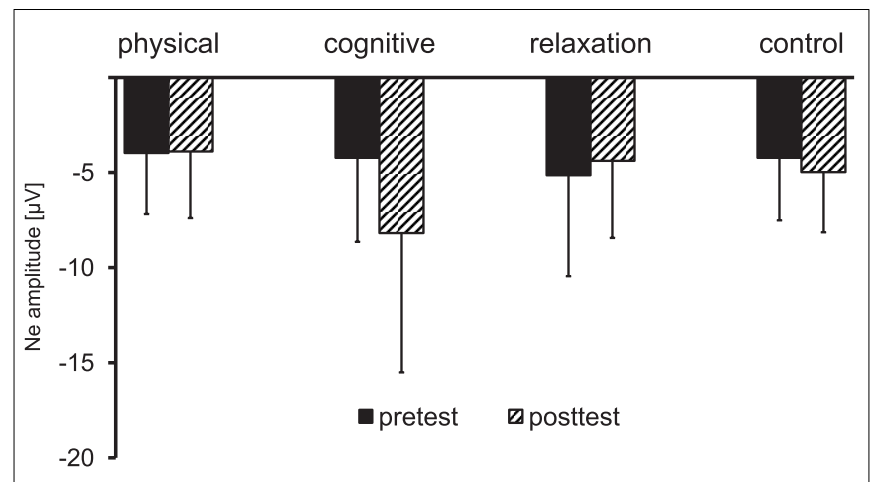

FIGURE 7 | Mean peak amplitude of the error negativity (Ne) collapsed across non-switch and switch trials as a function of session (pre vs. post) and group. The error bars reflect standard deviation (SD).

the physical, cognitive and relaxation group, respectively, answered "Yes." The question "How much did you benefit from training" was answered by $85 \%$ of the participants of the physical group "very much" or "much," whereas 79 and $66 \%$ of the participants of the cognitive and the relaxation training did so. The question "Do you feel physically better than before the training?": 79,28 , and $43 \%$ answered "much" or "very much." The question "Do you feel mentally better than before the training?": 38 , 54 , and 29\% "much" or "very much," for the physical, the cognitive and the relaxation group, respectively. Finally, the question "Do you intend to continue the training after the study is finished?": 73, 56, and 47\% answered "Yes," and 21, 40, and $41 \%$ "Maybe."

In summary, the subjects subjectively profited from all three interventions; the most fun and subjective benefit was experienced by the participants of the physical training group.

\section{DISCUSSION}

The aim of the present study was to investigate neurocognitive changes in aging due to qualitatively different types of training. To this end, 141 participants were randomly assigned to four groups consisting of physical training, cognitive training, relaxation training (contact control), and passive (no-contact control) group. Generally, no group differences were found in mean reaction times neither for mixing nor for local effects. Thus, it appears that different types of training do not affect reaction times in seniors at least in the present study. However, more sensitive behavioral parameters were intraindividual variability of speed and error rates.

In search for differential group effects in mixing costs, the most consistent benefits were found for the cognitive training group. In particular, cognitive training led to a substantial reduction of intraindividual variability of RTs and to a substantial reduction of mixing costs in accuracy. Regarding local effects we found lower RT-Variability in speed after training in all groups but the physical group and reduction of error rates in all groups relative to the no-contact control group. Yet, the strongest decrease of error rates was again found for the cognitive training group as indexed by a reliable contrast between this group and the no-contact group.
The electrophysiological markers should help to differentiate between sub-processes that were susceptible to training. Indeed, the mixing and local improvements in performance were associated with changes in event-related potentials. Overall, N2, P3b, and Ne were found to be enhanced after the cognitive training.

Firstly, during task implementation the identified target stimulus has to be associated with a particular task rule that enables selection of a response. In this phase an enhancement of the frontocentral N2 after cognitive training in the mixing task block was found. This enhancement in the stimulus-locked averages is not likely a simple reflection of the enhancement of the $\mathrm{Ne}$ in the response-locked averages (see below), because the N2 was measured in correct trials only, while the Ne was measured in the error trials, and no difference was found for the $\mathrm{Nc}$ in the responselocked correct trials. Our previous studies suggest that N2 reflects the process of response selection which is delayed by conflict or task set interference (Gajewski et al., 2008, 2010a, 2011). In other words, the $\mathrm{N} 2$ appears to reflect a decision process, as already proposed decades ago (Ritter et al., 1979, 1982; Towey et al., 1980). Therefore, the increased N2 after cognitive training suggests an improvement of response selection in general and hence, lower error rates and less speed variability after the training. This was supported by positive correlations between N2 latency and RTs and $\mathrm{Ne}$ amplitude and error rates, particularly after the training. As the $\mathrm{N} 2$ increase after cognitive training was related to a decrease of intraindividual variability of speed, it is plausible to assume that the lower the variability of the response selection process the lower the variability in RTs. Thus, the training-induced N2 increase in the average ERP may not only occur due to an elevation of the N2 amplitude, but also in consequence of a better synchronization of the N2 with the target and response in every trial, which should result in a larger component in the average ERP.

Secondly, the P3b was substantially enhanced both in the single and mixing blocks in the cognitive training group, suggesting generally higher available cognitive resources to perform the task (Kok, 2001), which may also be interpreted as enhanced neuronal integrity supported by reduced intraindividual variability of RTs.

Regarding local effects, the physical training led to a reduction of the P3b in switch relative to non-switch trials. This $\mathrm{P} 3 \mathrm{~b}$ pattern is usually observed in young subjects during switching tasks (e.g., Barceló et al., 2000; Lorist et al., 2000; Rushworth et al., 2002) that is mainly due to an increased N2 in the switch trials (Gajewski and Falkenstein, 2011b). However, this pattern was not observed before the training in the physical training group. The emergence of this pattern may correspond to the reduction of behavioral local switch costs after training (see Figures 2 and $\mathbf{3}$ ), which were particularly high at the pre-measure in this group. This suggests that the cognitive training generally enhanced the processing resources, resulting in lower global costs, while physical training specifically improved the switch process, resulting in lower local costs.

Finally, a highly consistent change was observed for the error negativity (Ne; Falkenstein et al., 1991), which was substantially increased after cognitive training only. We assume that the increase of the Ne is mainly a consequence of the improvement of response selection, as reflected in the enhanced N2. This implies that the enhanced cognitive resources indexed by the P3b led to a more efficient activation of stimulus-response associations in terms of 
response selection reflecting in the $\mathrm{N} 2$ and higher awareness about the required response, as reflected in an enhanced $\mathrm{Ne}$.

In sum, the results of the present study suggest that a multilayered formal cognitive training consisting of paper and penciland PC-based trainings led to an improvement of response selection processing capacity and error detection, which have not been demonstrated in previous studies.

One principal criticism of cognitive trainings is a rather limited transfer of brain training upon other non-trained functions or let alone daily life activities. Near transfer and far transfer to other cognitive functions has been reported when task switching was trained (Minear and Shah, 2008; Karbach and Kray, 2009). The present study also demonstrates a far transfer on mixing and local effects in accuracy, RT-variability, and ERPs, though our participants did not train task switching per se or other executive tasks but rather a broad range of basic functions like visual attention, short-term memory, speed of processing, visuospatial processing, and vigilance. Hence, the improvements in maintaining and coordinating task sets and selective reduction of error rates we found for the cognitive training group indicate some far transfer to not explicitly trained functions. However, it is quite possible that the improvement of performance after cognitive training is not restricted to the task switching situation. On the contrary, it is indeed plausible to assume that the improved response selection, processing capacity and error monitoring enhance performance in a number of other tasks. This should be tested in future training studies.

Existing literature showed repeatedly benefits of physical training on cognitive functions (e.g., Colcombe and Kramer, 2003). In the present study the physical training group decreased mixing and local costs in errors but this reduction was smaller than in the cognitive training group. We assume that the relatively short training duration of 4 months and frequency of two times per week with 90 min per session, was probably not sufficient to obtain strong training effects (c.f. Kramer and Erickson, 2007). This suggests that cognitive and physical training have different time ranges of efficiency, and future training studies should take this into account.

Finally, with regard to the relaxation training we included this group to control a confounding factor like new activity in a social context. To our knowledge, the prevailing literature reports no effect of relaxation training on cognitive functions in seniors. Of course, there is a strong connection between affective and cognitive functions as affective disorders or chronic stress impair cognitive functions like memory (McEwen, 2007). Thus, reduction of stress due to relaxation training may improve cognitive functions. However, as our participants dropped out from working life, no substantial level of stress was expected which may be diminished in course of the training. Nevertheless, similar to the physical and cognitive training groups, participants of the relaxation group reduced error rates relative to the no-contact group but again only if this group was tested together with the other training groups against the no-contact group. However, simple contrasts against the no-contact group did not reveal any reliable differences. The origin of this moderate effect cannot be unequivocally localized: it could be either due to the training intervention or was a by-product of a new experience in a social group. At least, we can clearly exclude the possibility that the improvement was induced by repeated measurements as no such benefit was found in the passive control group. Despite this effect, the participants of the relaxation group did not improve their performance to the extent of the cognitive training group.

There are some limitations of the study that deserve consideration. Firstly, the sample of the present study was selected from about 467 volunteers aged about 65 . The selection criteria like a good physical and mental constitution but no regular physical or mental activity in a sport club or association implies a discrepancy and induced a selection of relatively fit seniors. Therefore, our study is not representative for the average population but merely for a subpopulation of relatively fit persons, regardless of other sociodemographic variables. Since training effects are most likely larger for people with lower cognitive and physical status, we probably underestimated the training effects in the entire population. In future studies seniors with lower cognitive and physical status should be trained.

Secondly, as all trainings consisted of a number of sub-trainings and exercises, the crucial components that may lead to the specific improvement of performance remain unclear. Moreover, it is well possible that the three trainings differed in regard to other components, such as attractivity which may have affected training motivation. We aimed at creating varying and multilayered trainings in order to avoid monotony and to enhance the motivation for all three active groups but the motivation was not directly measured. Nevertheless, a post-training questionnaire provides some information regarding the subjective benefits, fun and the behavioral changes due to the training and the motivation to continue the training individually. By tendency, the physical group experienced qualitatively the most fun and subjective benefits, followed by the cognitive and relaxation group. This argues against motivation as crucial factor for the high benefits in the cognitive group.

Finally, the reason for the improvements in accuracy and variability of speed but not in the mean reaction times may be due to a particular difficult experimental paradigm including three tasks. The error rates were considerably high at pre-measure, which allowed enough space for improvement. More extensive pre-experimental practice would reduce a priori error rates and possibly reveal effects on reaction times as showed in other studies (e.g., Karbach and Kray, 2009).

Taken together, results of the present study agree with findings obtained in other cognitive training studies with young (Klingberg et al., 2005; Jaeggi et al., 2008, 2011; Karbach and Kray, 2009) and older adults (Willis and Schaie, 1986; Willis et al., 2006; Bielak et al., 2007; Buschkuehl et al., 2008; Li et al., 2008; Dahlin et al., 2009; Klusmann et al., 2010). We found clear improvements particularly in accuracy and intraindividual speed variability due to formal cognitive training and could specify the loci of the training effects with ERPs. Moreover, our study provides evidence for some qualitative differences of the effects of physical and cognitive training, which were also supported by electrophysiological measures. This suggests a promising application of a combined training that may enhance a large scale of cognitive processing in older people and hence increase the chance of transfer to daily activities. 


\section{CONCLUSION}

The most consistent behavioral and neuronal changes in our training study occurred in the cognitive training group, which showed improvements in maintaining and coordinating multiple task sets indexed by reduced costs in accuracy and lower RT-variability. This finding was supported by an increased frontocentral N2, suggesting improved and/or more synchronized response selection and an enhanced $\mathrm{P} 3 \mathrm{~b}$, indicating a better allocation of cognitive resources and higher processing capacity. Finally, the considerable reduction of error rates in the mixed block was associated with enhanced error detection indexed by an increased $\mathrm{Ne}$, which may be a consequence of the improved response selection. These results indicate that the behavioral improvements are mainly due to improvements in response selection which also leads to better error detection.

\section{REFERENCES}

Allport, A., Styles, E. A., and Hsieh, S. (1994). "Shifting intentional set: exploring the dynamic control of tasks," in Attention and Performance $X V$, eds C. Umiltà and M. Moscovitch (Cambridge, MA: MIT Press), 421-452.

Ball, K., Berch, D. B., Helmers, K. F., Jobe, J. B., Leveck, M. D., Marsiske, M., Morris, J. N., Rebok, G. W., Smith, D. M., Tennstedt, S. L., Unverzagt, F. W., and Willis, S. L. (2002). Effects of cognitive training interventions with older adults - a randomized controlled trial. JAMA 288, 2271-2281.

Ball, K., Edwards, J. D., and Ross, L. A. (2007). The impact of speed of processing training on cognitive and everyday functions. J. Gerontol. B Psychol. Sci. Soc. Sci. 62, 19-31.

Baltes, P. B., and Lindenberger, U. (1997). Emergence of a powerful connection between sensory and cognitive functions across the adult life span: a new window to the study of cognitive aging? Psychol. Aging 12, 12-21.

Band, G. P. H., and Kok, A. (2000). Age effects on response monitoring in a mental rotation task. Biol. Psychol. 51, 201-221.

Barceló, F., Muñoz-Céspedes, J. M., Pozo, M. A., and Rubia, F. J. (2000). Attentional set shifting modulates the target $\mathrm{P} 3 \mathrm{~b}$ response in the Wisconsin card sorting test. Neuropsychologia 38, 1342-1355.

Basak, C., Boot, W. R., Voss, M. W., and Kramer, A. F. (2008). Can training in a real-time strategy video game attenuate cognitive decline in older adults? Psychol. Aging 23, 765-777.

Becic, E., Boot, W. R., and Kramer, A. F. (2008). Training older adults to search more effectively: scanning strategy and visual search in dynamic displays. Psychol. Aging 23, 461-466.

Beck, A. T., Ward, C. H., Mendelson, M., Mock, J., and Erbaugh, J. (1961). An inventory for measuring depression. Arch. Gen. Psychiatry 4, 561-571.

Bherer, L., Kramer, A. F., Peterson, J. S., Colcombe, S., Erickson, K., and Becic, E. (2005). Training effects on dual-task performance: are there age-related differences in plasticity of attentional control? Psychol. Aging 20, 695-709.

Bielak, A. A., Hughes, T. F., Small, B. J., and Dixon, R. A. (2007). It's never too late to engage in lifestyle activities: significant concurrent but not change relationships between lifestyle activities and cognitive speed. J. Gerontol. B Psychol. Sci. Soc. Sci. 62, 331-339.

Buschkuehl, M., Jaeggi, S. M., Hutchison, S., Perrig-Chiello, P., Däpp, C., Müller, M., Breil, F., Hoppeler, H., and Perrig, W. J. (2008). Impact of working memory training on memory performance in old-old adults. Psychol. Aging 23 , 743-753.

Caserta, R. J., Young, J., and Janelle, C. M. (2007). Old dogs, new tricks: training the perceptual skills of senior tennis players. J. Sport Exerc. Psychol. 29, 479-497.

Cassavaugh, N., and Kramer, A. F. (2009). Transfer of computer-based cognitive training to simulated driving in older adults. Appl. Ergon. 40, 943-952.

Cepeda, N. J., Kramer, A. F., and Gonzalez de Sather, J. C. (2001). Changes in executive control across the life span: examination of task-switching performance. Dev. Psychol. 37, 715-730.

Colcombe, S., and Kramer, A. F. (2003). Fitness effects on the cognitive function of older adults: a meta-analytic study. Psychol. Sci. 14, 125-130.

These findings suggest neurocognitive plasticity of aging brains which can be stimulated not only by aerobic training but also by broad and multilayered paper and pencil and PC-based cognitive training, which also transfers to not directly trained functions. To our knowledge, this is the first study that demonstrates effects of cognitive training with ERP measures.

\section{ACKNOWLEDGMENTS}

This work was funded by a grant from the German Insurance Association (GDV, Gesamtverband der Deutschen Versicherungswirtschaft). We thank Ludger Blanke for programming the task and technical support and Christiane Westedt, Brita Rietdorf, Claudia Wipking and Pia Deltenre for their help in organization and conduction of the study, Sven Thoenes for his help in editing this manuscript and the two reviewers for their thoughtful comments.

Colcombe, S. J., Kramer, A. F., Erickson, K. I., Scalf, P., McAuley, E., Cohen, N. J., Webb, A., Jerome, G. J., Marquez, D. X., and Elavsky, S. (2004). Cardiovascular fitness, cortical plasticity, and aging. Proc. Natl. Acad. Sci. U.S.A. 101, 3316-3321.

Costa, P. T. Jr., and McCrae, R. R. (1992). Revised NEO Personality Inventory (NEO-PI-R) and NEO Five-Factor Inventory (NEO-FFI) Professional Manual. Odessa: Psychological Assesment Ressources, Inc.

Craik, F. I. M., and Salthouse, T. A. (eds). (2000) The Handbook of Aging and Cognition, 2nd Edn. Mahwah, NJ: Erlbaum.

Dahlin, E., Bäckman, L., Neely, A. S., and Nyberg, L. (2009). Training of the executive component of working memory: subcortical areas mediate transfer effects. Restor. Neurol. Neurosci. 27, 405-419.

De Jong, R. (2001). Adult age differences in goal activation and goal maintenance. Eur. J. Cogn. Psychol. 13, 71-89.

Donchin, E. (1981). Surprise!... Surprise? Psychophysiology 18, 493-513.

Donchin, E., and Coles, M. G. H. (1988) Is the P300 component a manifestation of context updating? Behav. Brain Sci. 11, 357-374.

Düzel, E., Bunzeck, N., Guitart-Masip, M., and Düzel, S. (2010). Noveltyrelated motivation of anticipation and exploration by dopamine (NOMAD): implications for healthy aging. Neurosci. Biobehav. Rev. 34, 660-669.

Edwards, J. D., Myers, C., Ross, L. A., Roenker, D. L., Cissell, G. M., McLaughlin, A. M., and Ball, K. K. (2009). The longitudinal impact of cognitive speed of processing training on driving mobility. Gerontologist 49, 485-494.
Erickson, K. I., Voss, M. W., Prakash, R. S., Basak, C., Szabo, A., Chaddock, L., Kim, J. S., Heo, S., Alves, H., White, S. M., Wojcicki, T. R., Mailey, E., Vieira, V. J., Martin, S. A., Pence, B. D., Woods, J. A., McAuley, E., and Kramer, A. F. (2011). Exercise training increases size of hippocampus and improves memory. Proc. Natl. Acad. Sci. U.S.A. 108, 3017-3022.

Falkenstein, M., Hohnsbein, J., and Hoormann, J. (1991). Effects of crossmodal divided attention on late ERP components. II. Error processing in choice reaction tasks. Electroencephalogr. Clin. Neurophysiol. 78, 447-455.

Falkenstein, M., Hoormann, J., Christ, S., and Hohnsbein, J. (2000). ERP components on reaction errors and their functional significance: a tutorial. Biol. Psychol. 51, 87-107.

Falkenstein, M., Hoormann, J., and Hohnsbein, J. (2001). Changes of error-related ERPs with age. Exp. Brain Res. 138, 258-262.

Falkenstein, M., Hoormann, J., and Hohnsbein, J. (2002). Inhibitionrelated ERP components: variation with age and time-on-task. J. Psychophysiol. 16, 167-175.

Folstein, M. F., Folstein, S. E., and McHugh, P. R. (1975). Mini-mental state. A practical method for grading the cognitive state of patients for the clinican. J. Psychiatr. Res. 12, 189-198.

Frick, K. M., and Fernandez, S. M. (2003). Enrichment enhances spatial memory and increases synaptophysin levels in aged female mice. Neurobiol. Aging 24, 615-626.

Gajewski, P. D., and Falkenstein, M. (2011a). Neurocognition of aging in working einvironments. J. Labour Market Res. 44, 307-320. 
Gajewski, P. D., and Falkenstein, M. (2011b). Diversity of the P3 in the task-switching paradigm. Brain Res. 1411, 87-97.

Gajewski, P. D., Hengstler, J., Golka, K., Falkenstein, M., and Beste C. (2011). The Met-allele of the BDNF Val66Met polymorphism enhances task switching in elderly. Neurobiol. Aging 32, 2327.e7-2327.e19.

Gajewski, P. D., Kleinsorge, T., and Falkenstein, M. (2010a). Electrophysiological correlates of residual switch costs. Cortex 46, 1138-1148.

Gajewski, P. D., Wild-Wall, N., Schapkin, S. A., Erdmann, U., Freude, U., and Falkenstein, M. (2010b). Effects of aging and job demands on cognitive flexibility assessed by task switching. Biol. Psychol. 85, 187-199.

Gajewski, P. D., Stoerig, P., and Falkenstein, M. (2008). ERP - correlates of response selection in a response conflict paradigm. Brain Res. 1189 , 127-134.

Gehring, W. J., Goss, B., Coles, M. G., and Meyer, D. E. (1993). A neural system for error detection and compensation. Psychol. Sci. 4, 385-390.

Gopher, D., Weil, M., and Bareket, T. (1994). Transfer of skill from a computer game trainer to flight. Hum. Factors 36, 387-405.

Gratton, G., Coles, M. G. H., and Donchin, E. (1983). A new method for off-line removal of ocular artifact. Electroencephalogr. Clin. Neurophysiol. 55, 468-484.

Green, C., and Bavelier, D. (2003). Action video game modifies visual selective attention. Nature 423, 534-537.

Greenwood, P. M. (2007). Functional plasticity in cognitive aging: review and hypothesis. Neuropsychology 21, 657-673.

Greenwood, P. M., and Parasuraman, R. (2010). Neuronal and cognitive plasticity: a neurocognitive framework for ameliorating cognitive aging. Front. Aging Neurosci. 2:150. doi:10.3389/fnagi. 2010.00150

Hertzog, C., Kramer, A. F., Wilson, R. S., and Lindenberger, U. (2008). Enrichment effects on 656 adult cognitive development. Psychol. Sci. Public Interest 9, 1 .

Hertzog, C., Kramer, A. F., Wilson, R. S., and Lindenberger, U. (2009). Enrichment effects on adult cognitive development: can the functional capacity of older adults be preserved and enhanced? Psychol. Sci. Public Interest 9, 1-65.

Heyn, P., Abreu, B. C., and Ottenbacher, K. J. (2004). The effects of exercise training on elderly persons with cognitive impairment and dementia: a meta-analysis. Arch. Phys. Med. Rehabil. 85, 1694-1704.

Hillman, C. H., Erickson, K. I., and Kramer, A. F. (2008). Be smart, exercise your heart: exercise effects on brain and cognition. Nat. Rev. Neurosci. 9, 58-65.

Hultsch, D. F., Hertzog, C., Small, B. J., and Dixon, R. A. (1999). Use it or lose it: engaged lifestyle as a buffer of cognitive decline in aging? Psychol. Aging 14, 245-263.

Hultsch, D. F., and MacDonald, S. W. S. (2004). "Intraindividual variability in performance as a theoretical window onto cognitive aging," in New Frontiers in Cognitive Aging, eds R. A. Dixon, L. Backman, and L.-G. Nilsson (Oxford: Oxford University Press), 65-88.

Ilg, R., Wohlschlager, A. M., Gaser, C., Liebau, Y., Dauner, R., Woller, A., and Zimmer C, Zihl J, Mühlau M. (2008). Gray matter increase induced by practice correlates with task-specific activation: a combined functional and morphometric magnetic resonance imaging study. J. Neurosci. 28, 4210-4215.

Jaeggi, S. M., Buschkuehl, M., Jonides, J., and Perrig, W. J. (2008). Improving fluid intelligence with training on working memory. Proc. Natl. Acad. Sci. U.S.A. 105, 6829-6833.

Jaeggi, S. M., Buschkuehl, M., Jonides, J., and Shah, P. (2011). Short- and longterm benefits of cognitive training. Proc. Natl. Acad. Sci. U.S.A. 108, 10081-10086.

Jasper, H. H. (1958). The 10-20 electrode system of the International Federation. Electroencephalogr. Clin. Neurophysiol. 10, 370-375.

Jones, S., Nyberg, L., Sandblom, J., Stigsdotter Neely, A., Ingvar, M., Magnus Petersson, K., and Bäckman L. (2006). Cognitive and neural plasticity in aging: general and task-specific limitations. Neurosci. Biobehav. Rev. 30, 864-871.

Karbach, J., and Kray, J. (2009). How useful is executive control training? Age differences in near and far transfer of task-switching training. Dev. Sci. 12, 978-990.

Kempermann, G., Kuhn, H. G., and Gage, F. H. (1997). More hippocampal neurons in adult mice living in an enriched environment. Nature 386, 493-495.

Kiesel, A., Steinhauser, M., Wendt, M., Falkenstein, M., Jost, K., Phillip, A., and Koch, I. (2010). Control and interference in task switching - a review. Psychol. Bull. 136, 849-874.

Klingberg, T., Fernell, E., Olesen, P. Johnson, M., Gustafsson, P., and
Dahlstrom, K Gillberg CG, Forssberg H, Westerberg H. (2005). Computerized training of working memory in children with ADHD - a randomized, controlled trial. J. Am. Acad. Child Adolesc. Psychiatry 44, 177-186.

Klingberg, T., Forssberg, H., and Westerberg, H. (2002). Training of working memory in children with ADHD. J. Clin. Exp. Neuropsychol. 24, 781-791.

Klusmann, V., Evers, A., Schwarzer, R. Schlattmann P., Reischies, F. M. Heuser, I., and Dimeo, F. C. (2010). Complex mental and physical activity in older women and cognitive performance: a 6-month randomized controlled trial. J. Gerontol. A Biol. Sci. Med. Sci. 65, 680-688.

Kok, A. (2001). On the utility of P3 amplitude as a measure of processing capacity. Psychophysiology 38, 557-577.

Kolev, V., Falkenstein, M., and Yordanova, J. (2005). Aging and error processing. Time-frequency analysis of error-related potentials. J. Psychophysiol. 19, 289-297.

Kramer, A. F., and Erickson, K. I. (2007). Effects of physical activity on cognition, well-being and brain: human interventions. Alzheimers Dement. 3 , 45-51.

Kramer, A. F., Erickson, K. I., and Colcombe, S. J. (2006). Exercise, cognition, and the aging brain. J. Appl. Physiol. 101, 1243-1251.

Kramer, A. F., Hahn, S., and Gopher, D. (1999). Task coordination and aging: explorations of executive control processes in the task switching paradigm. Acta Psychol. 101, 339-378.

Kramer, A. F., and Morrow, D. (in press). "Cognitive training and expertise," in Cognitive Aging: A Primer, eds D. Park and N. Schwartz (Philadelphia: Psychology Press).

Kray, J. (2006). Task-set switching under cue-based versus memory-based switching conditions in younger and older adults. Brain Res. 1105, 83-92.

Kray, J., Eber, J., and Lindenberger, U. (2004). Age differences in executive functioning across the lifespan: the role of verbalization in task preparation. Acta Psychol. 115,143-165.

Kray, J., and Lindenberger, U. (2000). Adult age differences in task switching. Psychol. Aging 15, 126-147.

Lehrl, S., Lehrl, M., and Weickmann, E. (1994). MAT Gehirnjogging, Einführung in das Mentale AktivierungsTraining. Ebersberg: Vless Verlag.

Lehrl, S., Triebig, G., and Fischer, B. (1995). Multiple choice vocabulary test MWT as a valid and short test to estimate premorbid intelligence. Acta Neurol. Scand. 91, 335-345.

Li, S. C., Schmiedek, F., Huxhold, O., Röcke, C., Smith, J., and Lindenberger, U. (2008). Working memory plasticity in old age: practice gain, transfer, and maintenance. Psychol. Aging 23, 731-742.

Lindenberger, U., Nagel, I. E., Chicherio, C., Li, S., Heekeren, H. R., and Bäckman, L. (2008). Age-related decline in brain resources modulates genetic effects on cognitive functioning. Front. Neurosci. 2:2. doi:10.3389/neuro.01.039.2008

Liu-Ambrose, T., Nagamatsu, L. S., Graf, P., Beattie, B. L., Ashe, M. C., and Handy, T. C. (2010). Resistance training and executive functions: a 12-month randomized controlled trial. Arch. Intern. Med. 170, 170-178.

Lorist, M. M., Klein, M., Nieuwenhuis, S., De Jong, R., Mulder, G., and Meijman, T. F. (2000). Mental fatigue and task control: planning and preparation. Psychophysiology 37, 614-625.

Lustig, C., Shah, P., Seidler, R., and Reuter-Lorenz, P. A. (2009). Aging, training, and the brain: a review and future directions. Neuropsychol. Rev. 19, 504-522.

Mayr, U. (2001). Age differences in the selection of mental sets: the role of inhibition, stimulus ambiguity, and response-set overlap. Psychol. Aging 16, 96-109.

Mayr, U., and Liebscher, T. (2001). Is there an age deficit in the selection of mental sets? Eur. J. Cogn. Psychol. 13, 47-69.

McAuley, E., Kramer, A. F., and Colcombe, S. J. (2004). Cardiovascular fitness and neurocognitive function in older adults: a brief review. Brain Behav. Immun. 18, 214-220.

McEwen, B. S. (2007). Physiology and neurobiology of stress and adaptation: central role of the brain. Physiol. Rev. 87, 873-904.

Meiran, N. (1996). Reconfiguration of processing mode prior to task performance. J. Exp. Psychol. Learn. Mem. Cogn. 22, 1423-1442.

Meiran, N., Gotler, A., and Perlman, A. (2001). Old age is associated with a pattern of relatively intact and relatively impaired task-set switching abilities. J. Gerontol. B Psychol. Sci. Soc. Sci. 56, 88-102.

Milgram, N., Siwak-Tapp, C., Araujo, J., and Head, E. (2006). Neuroprotective effects of cognitive enrichment. Ageing Res. Rev. 5, 354-369.

Minear, M., and Shah, P. (2008). Training and transfer effects in 
task switching. Mem. Cognit. 36, 1470-1483.

Mozolic, J. L., Hayasaka, S., and Laurienti, P. J. (2010). A cognitive training intervention increases resting cerebral blood flow in healthy older adults. Front. Hum. Neurosci. 4:16. doi:10.3389/neuro.09.016.2010

Pereira, A. C., Huddleston, D. E., Brickman, A. M., Sosunov, A. A., Hen, R., McKhann, G. M., Sloan, R., Gage, F. H., Brown, T. R., and Small, S. A. (2007). An in vivo correlate of exercise-induced neurogenesis in the adult dentate gyrus. Proc. Natl. Acad. Sci. U.S.A. 104, 5638-5643.

Polich, J. (2007). Updating P300: an integrative theory of $\mathrm{P} 3 \mathrm{a}$ and $\mathrm{P} 3 \mathrm{~b}$. Clin. Neurophysiol. 118,128-148.

Ram, N., Stollery, B., Rabbit, P., and Nesselroade, J. R. (2005). Cognitive performance inconsistency: intraindividual change and variability. Psychol. Aging 20, 623-633.

Reinke, K. S., He, Y., Wang, C., and Alain, C. (2003). Perceptual learning modulates sensory evoked response during vowel segregation. Brain Res. 17, 781-791.

Ritter, W., Simson, R., and Vaughan, H. G. Jr. (1983). Event-related potential correlates of two stages of information processing in physical and semantic discrimination tasks. Psychophysiology 20, 168-179.

Ritter, W., Simson, R., Vaughan, H. G. Jr., and Friedman, D. (1979). A brain event related to the making of a sensory discrimination. Science 203, 1358-1361.

Ritter, W., Simson, R., Vaughan, H. G. Jr, and Macht M. (1982). Manipulation of event-related potential manifestations of information processing stages. Science 218, 909-911.

Roche, R. A., and O'Mara, S. M. (2003). Behavioural and electrophysiological correlates of visuomotor learning during a visual search task. Brain Res. 15, 127-136.
Rogers, R. D., and Monsell, S. (1995). Costs of a predictable switch between simple cognitive tasks. J. Exp. Psychol. Gen. 124, 207-231.

Rushworth, M. F., Passingham, R. E., and Nobre, A. C. (2002). Components of switching intentional set. J. Cogn. Neurosci. 14, 1139-1150.

Salthouse, T. A. (2009). When does age-related cognitive decline begin? Neurobiol. Aging 30, 507-514.

Singh-Manoux, A., Richards, M., and Marmot, M. (2003). Leisure activities and cognitive function in middle age: evidence from the Whitehall II study. J. Epidemiol. Community 57, 907-913.

Smiley-Oyen, A. L., Lowry, K. A., Francois, S. J., Kohut, M. L., and Ekkekakis, P. (2008). Exercise, fitness, and neurocognitive function in older adults: the "selective improvement" and "cardiovascular fitness" hypothesis. Ann. Behav. Med. 36, 280-291.

Song, Y., Ding, Y., Fan, S., Qu, Z., Xu, L., Lu, C., and Peng D. (2005). Neural substrates of visual perceptual learning of simple and complex stimuli. Clin. Neurophysiol. 116, 632-639.

Swaab, D. F., and Bao, A. M. (2011) $(\mathrm{Re}-)$ activation of neurons in aging and dementia: lessons from the hypothalamus. Exp. Gerontol. 46, 178-184.

Takeuchi, H., Sekiguchi, A., Taki, Y., Yokoyama, S., Yomogida, Y., Komuro, N., and Yamanouchi T, Suzuki S, Kawashima R. (2010). Training of working memory impacts structural connectivity. J. Neurosci. 30, 3297-3303.

Tong, Y., Melara, R. D., and Rao, A. (2009). P2 enhancement from auditory discrimination training is associated with improved reaction times. Brain Res. 1297, 80-88.

Towey, J., Rist, F., Hakerem, G., Ruchkin, D. S., and Sutton, S. (1980). N250 latency and decision time. Bull. Psychon. Soc. 15, 365-368. van Praag, H., Kempermann, G. and Gage, F. H. (1999). Running increases cell proliferation and neurogenesis in the adult mouse dentate gyrus. Nat. Neurosci. 2, 266-270.

van Praag, H., Shubert, T., Zhao, C., and Gage, F. H. (2005). Exercise enhances learning and hippocampal neurogenesis in aged mice. J. Neurosci. 25, 8680-8685.

Verhaeghen, P., and Cerella, J. (2002). Aging, executive control, and attention: a review of meta-analyses. $\mathrm{Neu}$ rosci. Biobehav. Rev. 26, 849-857.

Voelcker-Rehage, C., Godde, B. and Staudinger, U. M. (2011). Cardiovascular and coordination training differentially improve cognitive performance and neural processing in older adults. Front. Hum. Neurosci. 17:26. doi:10.3389/fnhum.2011.00026

West, R., and Travers, S. (2008). Differential effects of aging on processes underlying task switching. Brain Cogn. 68, 67-80.

Whitlock, J. R., Heynen, A. J., Shuler, M. G., and Bear, M. F. (2006). Learning induces long-term potentiation in the hippocampus. Science 313 1093-1097.

WHOQOL Group. (1998). Development of the World Health Organization WHOQOL-BREF quality of life assessment. Psychol. Med. 28, 551-558.

Willis, S. L., and Schaie, K. W. (1986). Training the elderly on the ability factors of spatial orientation and inductive reasoning. Psychol. Aging 1, 239-247.

Willis, S. L., Tennstedt, S. L., Marsiske, M., Ball, K., Elias, J., Koepke, K. M., Morris, J. N., Rebok, G. W., Unverzagt, F. W., Stoddard, A. M., and Wright, E. (2006). ACTIVE Study Group. Long-term effects of cognitive training on everyday functional outcomes in older adults. JAMA 296, 2805-2814.
Wiskott, L., Rasch, M. J., and Kempermann, G. A. (2006). Functional hypothesis for adult hippocampal neurogenesis: avoidance of catastrophic interference in the dentate gyrus. Hippocampus 16, 329-343.

Zehnder, F., Martin, M., Altgassen, M., and Clare, L. (2009). Memory training effects in old age as markers of plasticity: a metaanalysis. Restor. Neurol. Neurosci. 27, 507-520.

Conflict of Interest Statement: The authors declare that the research was conducted in the absence of any commercial or financial relationships that could be construed as a potential conflict of interest. There are no actual or potential conflicts of interests. The informed consent of the participants was obtained and their rights were protected throughout the experiments according with the ethical standards in the Declaration of Helsinki. The study was approved by the local ethics committee.

Received: 05 December 2011; paper pending published: 13 January 2012; accepted: 20 April 2012; published online: 11 May 2012.

Citation: Gajewski PD and Falkenstein M (2012) Training-induced improvement of response selection and error detection in aging assessed by task switching: effects of cognitive, physical, and relaxation training. Front. Hum. Neurosci. 6:130. doi: 10.3389/fnhum.2012.00130

Copyright (C) 2012 Gajewski and Falkenstein. This is an open-access article distributed under the terms of the Creative Commons Attribution Non Commercial License, which permits non-commercial use, distribution, and reproduction in other forums, provided the original authors and source are credited. 


\section{APPENDIX \\ DESCRIPTION AND SCHEDULE OF EXERCISES INCLUDED IN THE COGNITIVE TRAINING}

The schedule of the cognitive training is presented in Table A1. MAT (www.gfg-online.de) is a paper and pencil package with short exercises which had to be applied for $10 \mathrm{~min}$ daily to increase working memory capacity, visual attention, and speed of information processing. In particular, the training aimed at enhancing psychomotor processing by faster perceiving and responding to objects or words, for example detection of triangles in a complex geometric figure or identification of words in a complex letter matrix, which were arranged either vertically, horizontally, or diagonally. Memory training included exercises that used words, figures, or digits. Participants were asked to memorize the items from each category and recall as many items as possible after several minutes. A more complex exercise consisted of association between faces and personal data like age and profession and recalling the information after a face presentation $10 \mathrm{~min}$ later.

The training begins with easy exercises to make quick effects possible. By creating more challenging instructions and by

Table A1 | A schedule of the cognitive training program.

\begin{tabular}{|c|c|c|}
\hline Week & Session & Exercise \\
\hline \multirow[t]{2}{*}{1} & 1 & MAT \\
\hline & 2 & MAT \\
\hline \multirow[t]{2}{*}{2} & 3 & MAT \\
\hline & 4 & MAT \\
\hline \multirow[t]{2}{*}{3} & 5 & MAT \\
\hline & 6 & MAT/Sudoku \\
\hline \multirow[t]{2}{*}{4} & 7 & MAT/Sudoku \\
\hline & 8 & MAT/Sudoku \\
\hline \multirow[t]{2}{*}{5} & 9 & Mental-Aktiv/Ahano/Sudoku \\
\hline & 10 & Mental-Aktiv/Ahano \\
\hline \multirow[t]{2}{*}{6} & 11 & Mental-Aktiv/Ahano \\
\hline & 12 & Mentaga/Mental-Aktiv/Ahano \\
\hline \multirow[t]{2}{*}{7} & 13 & Mentaga/Mental-Aktiv/Ahano \\
\hline & 14 & Mentaga/Ahano \\
\hline \multirow[t]{2}{*}{8} & 15 & Mentaga/Ahano \\
\hline & 16 & Mentaga/Ahano/Sudoku \\
\hline \multirow[t]{2}{*}{9} & 17 & Mentaga/Ahano/Sudoku \\
\hline & 18 & Mentaga/Sudoku \\
\hline \multirow[t]{2}{*}{10} & 19 & Mentaga/Sudoku \\
\hline & 20 & Mentaga/Sudoku \\
\hline \multirow[t]{2}{*}{11} & 21 & Mentaga \\
\hline & 22 & Mentaga \\
\hline \multirow[t]{2}{*}{12} & 23 & Mentaga/Ahano \\
\hline & 24 & Mentaga/Ahano \\
\hline \multirow[t]{2}{*}{13} & 25 & Mentaga/Sudoku \\
\hline & 26 & Mentaga/Ahano \\
\hline \multirow[t]{2}{*}{14} & 27 & Mentaga/Ahano \\
\hline & 28 & Mentaga/Ahano \\
\hline \multirow[t]{2}{*}{15} & 29 & Mentaga/Ahano \\
\hline & 30 & Mentaga \\
\hline \multirow[t]{2}{*}{16} & 31 & Mentaga/Ahano/Sudoku \\
\hline & 32 & Mentaga/Sudoku \\
\hline
\end{tabular}

allowing less time for task performance, the level of difficulty gets enhanced gradually.

The training consists of the following modules:

Information processing speed:

Time limited visual search. Different forms, numbers and letters are used. Identification of single words in randomly assembled sequences of letters. The hidden words are arranged forward, backward, vertically, horizontally, or diagonally.

\section{Memory span:}

Keep several numbers, words, or pictures in memory and immediate recall of words or identifying missing words.

Basic learning speed:

Memorization of faces with personal data and memorization of faces with distracting stimuli.

Mental-aktiv (www.mental-aktiv.de) is an internet-based platform that offers a number of memory tasks using digits, letters, colors, and figures and exercises to train speed of processing. The exercises were designed in cooperation with the authors of MAT and trained the same functions as listed above.

Sudoku is a logic-based number placement puzzle that consists from a $9 \times 9$ grid with digits so that each column, each row, and each of the nine $3 \times 3$ sub-grids contain all of the digits from 1 to 9 .

Ahano peds (www.ahano.de) consists of units with different levels of difficulty. The free available program includes an eyehand coordination task, money counting task, detection of word repetitions in a text, block taping task, memory for abstract figures etc.

Double:

There is a yellow ball and a red box presented on the screen. With one hand, the participant has to use the computer mouse in a certain way in order to put the ball into the box. With the other hand, the participant has to type the presented words as quickly as possible. This exercise trains peripheral visual attention as well as the coordination of multiple operations.

\section{Euro Coins:}

There are many different coins in a purse. The task is to assemble specific coins in order to reach a given amount. This should be done as often as possible within a specific interval. Visual perception, selective attention, and mental arithmetic are trained.

\section{Response:}

Balloons float past the window of an aircraft. The task is to click as quickly as possible on the relevant balloon appearing on the left side of the window. This exercise trains selective attention and distractor inhibition.

Palpation:

At the time when a green light appears on the screen, one of five given forms is hidden behind a big picture. The participant's task is to touch the form by use of the computer mouse in order to decide which form is hidden in the current trial. To make a choice, the participant has to click on the corresponding picture. There 
is only one attempt in each trial. This exercise trains perception and spatial-visual memory.

Double Words:

A pool of words is given, which contains each single word twice. The task is to click on the currently relevant word by use of the computer mouse. There are five attempts in each trial to find the correct word. This exercise trains the participant's memory.

\section{Chimpanzee test:}

Nine fields are presented containing single digits for a short time. After the digit's disappearance, the participants are instructed to click on the fields in ascending order to reproduce the positions, where the respective figures were shown. Here, visual perception, short-term memory and spatial-visual memory can be trained.

\section{Colors:}

The participants have to memorize the colors of a presented picture. The task is to "repaint" the image by first clicking on a "paint pot" and then clicking on the image area. The participants receive one point for each correctly chosen color. Visual perception, short-term memory and spatial-visual memory can be trained by this exercise.

Mentaga (www.mentaga.com) consists of exercises enhancing vigilance, perceptual speed, spatial attention etc. like comparison of visual patterns, face learning, counting, vigilance, and eye-hand coordination

Figurative Thinking:

In each trial, two, almost identical pictures are presented. There are exactly three differences between the two pictures, which the participant has to detect as quickly as possible. This exercise is designed to support selective attention.

\section{Capacity:}

The task is to catch vertically falling balls with a basket as accurately and quickly as possible. To adjust the basket, the participant has to use the computer mouse. Simultaneously, as many numerical and alphabetical tasks as possible have to be performed. Spatial-visual attention, arithmetic, concentration, and of multiple task performance should be improved by this task.
Concentration:

In each trial, an "E" surrounded by a certain number of dots is presented. The task is to identify every $\mathrm{E}$ which is surrounded exactly by three dots as quickly as possible. Concentration and visual attention are trained by this task.

\section{Pattern Matching:}

Four pictures are presented in each trial. There is always one original, two rotated versions of the original and one differing picture, which the participant has to identify by clicking on it. This exercise trains the abilities of mental rotation and visual search.

\section{Person Memory:}

This exercise aims at memorizing and recognizing names and faces. First, a sequence of faces and names is presented and the participants explicitly have to memorize the names. Then, faces are displayed with various names. The participant has to decide which name is related to a particular face. This exercise specifically trains object recognition.

Visual Acuity:

In each trial, two pictures are presented. As quickly as possible, the participant has to decide whether the two pictures are identical. Visual acuity and visual search are trained by this task.

Response Capacity:

Two objects are presented side by side. The participant has to decide whether the objects are identical. A response is required if the objects are identical. This exercise aims at improving visual search and decision time.

Memory for Numbers:

The participant has to memorize and reproduce numbers presented on the screen. The length of each number is adapted to the participant's capacity. The more digits a number contains, the more time is granted for memorizing and reproducing the number. Primarily, this exercise trains the memory for numbers, but also working memory in general. 